\title{
The Impact of Governance Rules on Earnings Management: Applied Study on Industrial and Service Companies Listed on Palestine Stock Exchange
}

Yousef Sameh Yousef Alrayyes*

Ministry of Information Technology,

Gaza Strip, Palestine

Email: acc.yousef@hotmail.com

\section{Nahed N Al Khaldy}

The Islamic University of Gaza,

Gaza Strip, Palestine.

Email: nkhaldy@iugaza.edu.ps

Received June, 2019; Accepted September, 2019

\begin{abstract}
The aim of the study is to analyze the impact of corporate governance rules on earnings management practiced by companies listed on Palestine Exchange. A number of corporate governance variables were selected to achieve this aim, including the board size of directors, CEO duality, board of director's independence, property rights, number of board directors' meetings. Modified Jones Model was used to detect earnings management. Panel Data Model was also involved in the study, where the population study consists of the 48 companies listed on Palestine Exchange. The study sample included 13 industrial and services companies listed on Palestine Exchange. This study found that there was a negative influence between board size and CEO duality, and between earnings management. The study also showed that there was a positive influence between board independence and earnings management. Moreover, it showed that no relationship between board directors' meetings and internal ownership with earnings management. The study stressed the need for continued reinforcement of the governance rules, in order to avoid the negative impacts resulted from failure to apply these rules, taking into consideration the support of board independence in their relationship with areas of executive work to avoid taking decisions that may affect earnings management. It also recommended that doing other researches on the same subject should be continued, taking into account the examination of variables other than those in this study to get to the variables that have the greatest impact on earnings management for companies listed on the Palestine Exchange.
\end{abstract}

Keywords: Corporate Governance; Earning Management; Modified Jones Model.

Type: Research paper

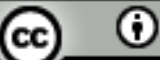

This work is licensed under a Creative Commons Attribution 4.0 International License.

\section{DOI: 10.51325/ijbeg.v2i3.51}

$$
\begin{aligned}
& \text { تأثير قواعد الحوكمة على إدارة الأرباح: دراسة تطبيقية على الثركات الصناعية والخدمية المدرجة في بورصة } \\
& \text { فلسطين } \\
& \text { الملخص: } \\
& \text { هدفت هذه الدراسـة إلى دراسـة أثر قواعد الحوكمة على إدارة الأرباح على الشركات المدرجة في بورصـة فلسطين } \\
& \text { للأوراق المالية، ولتحقيق هدف الدراسة تم اختيار عدد من المتغيرات المتعلقة بحوكمة الثركات وهي (عدد أعضساء } \\
& \text { مجلس الإدارة، ازدواجية منصب المدير التتفيذي، استقلالية مجلس الإدارة، حقوق الملكية الداخلية، عدد اجتماعات } \\
& \text { مجلس الإدارة)، وتم قياس إدارة الأرباح من خلال نموذج جونز المعدل من قبل (Dechow et al, 1995). وتم } \\
& \text { استخدام أسلوب بيانـات السلاسـل الزمنيـة المقطعيـة (Panel Data) حيث تكون مجتمع الدراسـة من الثـركات }
\end{aligned}
$$


المدرجة ببورصة فلسطين والتي يبلغ عددها (48) شركة، والموزعة على (5) قطاعات مختلفة. هذا، واشتملت عينة

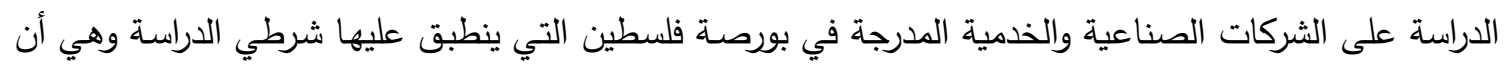
يكون لها بيانات مالية منشورة خلال الفترة من 2010 حتى 2017، إلى جانب تداول أسهرها خلال نفس الفترة، حيث بلغ عددها (13 شركة). وقد أظهرت نتائج الدراسة وجود تأثير عكسي بين كلاً من (حجم مجلس الإدارة،

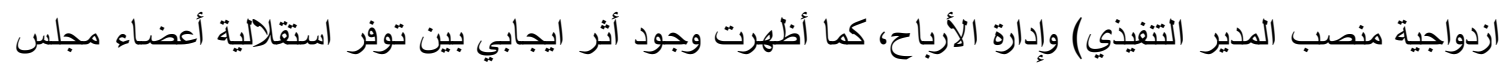
الإدارة وإدارة الأرباح، في حين أظهرت الدراسة غياب أي علاقة بين (عدد اجتماعات مجلس الإدارة، حقوق الملكية الداخلية) مع إدارة الأرباح. وأوصت الدراسة بضرورة الاستمرار في تعزيز قواعد الحوكمة لتلافي التأثيرات السلبية

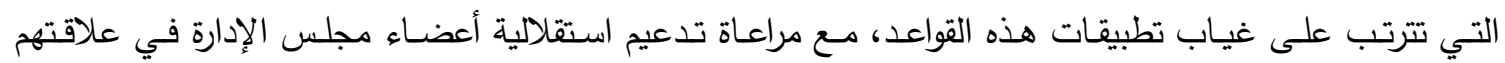

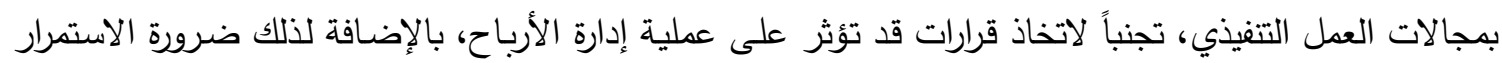

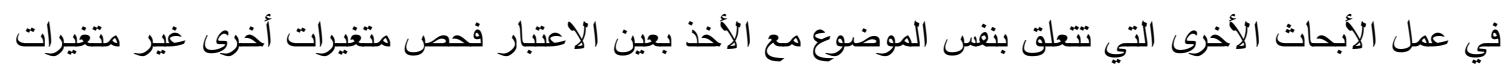

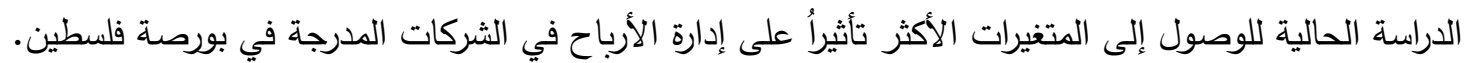
الكلمات المفتاحية: حوكمة الشركات، إدارة الأرباح، نموذج جونز المعدل (1995).

مقدمة الدراسة

شهدت نهاية القرن الماضي وبداية القرن الحالي، سلسلة من الفضائح المحاسبية للشركات في أغلب أنحاء العالم وخصوصاً في الولايات المتحدة الأمريكية وأوروبا نتيجة المرونة المتاحة في تطبيق المعايير المحاسبية التي تسهل ممارسة إدارة الأرباح من قبل إدارة الشركة، ويظهر ذلك واضاداً في الكثير من الجوانب المحاسبية التي لا تتوانى إدارة الشركة في استخدامها كوسيلة للتأثير على ارقام الربح الذي يلبي رغباتها ويلبي طموحاتها في تقييد أرباح ولو لون وهمية لانضمامها إلى البورصة مثلاً. ومن أجل تجنب ذلك أدخلت العديد من اللوائح والصلاحيات المتعلقة بقواعد تطبيق حوكمة الشركات لتجنب حدوث مثل هذه الأزمات ولنا في انهيار شركة Enron مثالاً، حيث يتم إلقاء اللوم على مدققي الحسابات والإدارة التتفيذية

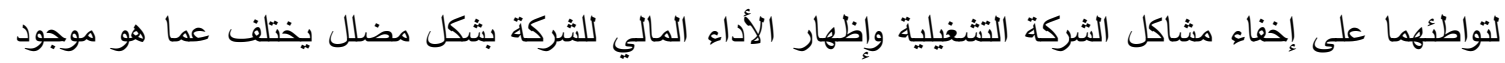
في الواقع بهدف تحقيق بعض المكاسب سواء للإدارة أو للددقق، الأمر الذي يزيد من خطر إفلاء الفاء هذه الثركات.

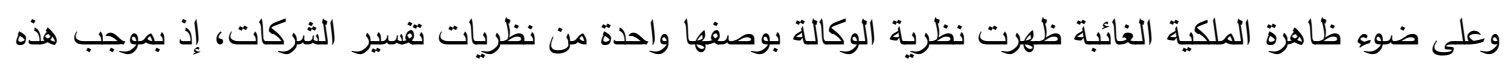
الظاهرة تفسر الشركة بأنها مجموعة من العلاقات التعاقدية الصريحة أو الضمنية بين طرفين وهما: حملة الأسهم (الموكل) والإدارة (الوكيل) بحيث يستوجب على الطرف الثاني (الوكيل) على أساسها القيام بأنثطة معينة لصالح

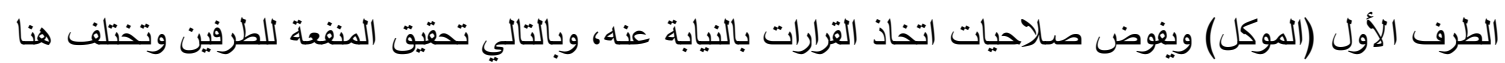

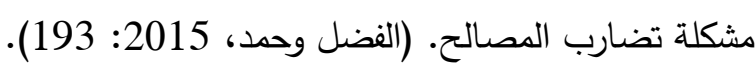

وفي ظل تفتت رأس مال الثركة بين عدد كبير من حملة الأسهم، تظهر هنا الحاجة إلى الاستعانة بالخبرات الإدارية

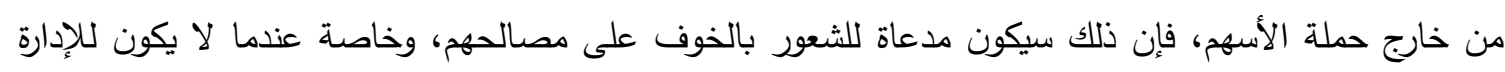

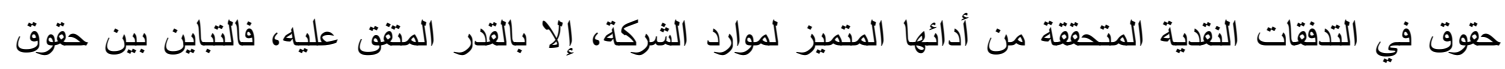

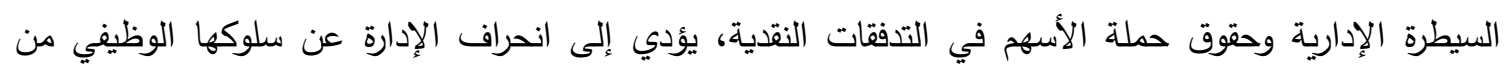

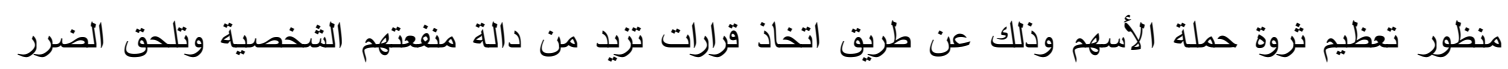
بمصالح حملة الأسهح لاسيما في حقوقهم غير المؤكدة المتمثلة في صافي التدفقات النقدية المتبقية من نواتج الأداء أو من صافي قيمة التصفية من جهة، وتزيد من مستوى تعرضهم لمخاطر الأعمال الناشئة من التباين بين التدفقات 
النقدية المتوقعة من الموارد المتاحة والتدفقات النقدية الخارجية المتقق عليها مع الإدارة من جهة ثانية، مما يعني حدوث تعارض في المصالح ومن ثم ظهور مشكلة الوكالة التي يمكن أن تتجسد بصورة الممارسات الإدارية الخاطئة أو الانتهازية. (Jensen \& Meckling, 1976)

وقد خطت فلسطين خطواتها الأولى في شباط من العام 2009 من قبل اللجنة الوطنية للحوكمة بالثراكة مع 13 مؤسسة ضمت مؤسسات مالية، واكاديميون، ومدققي حسابات، ومحامون بإصدار النسخة النهائية من مدونة قواعد حوكمة الثركات، هذا وقد اصدر سوق فلسطين للأوراق المالية في أغسطس من العام 2016م دليلا لحوكمة الشركات كخطوة ثانية لترسيخ مبادئ وقواعد الحوكمة لدى الشركات.

وبناءً على ما سبق ازداد الاهتمام من قبل الحكومات والمنظمات المهنية بحوكمة الشركات والتي تعتبر من أهم

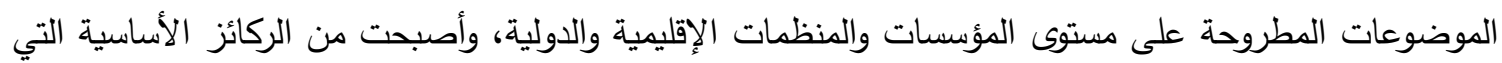

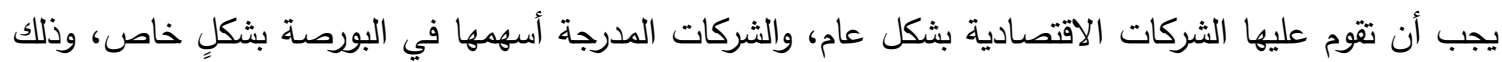
بتطبيق مجموعة من الآليات الداخلية والخارجية الموضوعة والتي من شأنها اكتثاف والحد من ممارسات المحاسبة الاحتيالية وإضفاء مصداقية على القوائم المالية الختامية للشركة بما يزيد من النمو الاقتصادي للدولة ويزيد من حجم

$$
\text { التعاملات في البورصة. }
$$

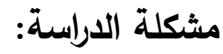
نظرا لما ترتب على هذه الظاهرة (إدارة الأرباح)، من تضليل وطمس للحقائق، والذي نجم عنه العديد من الفضائح

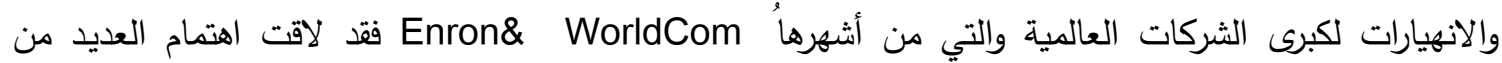
الباحثين والمهتمين، وفى هذا السياق فقد ألقى Arthur Levitt رئيس هيئة الأوراق المالية الأمريكية الأسبق(SEC) عام 1998)خطاباً مشهورا في مركز جامعة نيويورك للقانون والأعمال تحت عنوان (لعبة الأرقام) ،

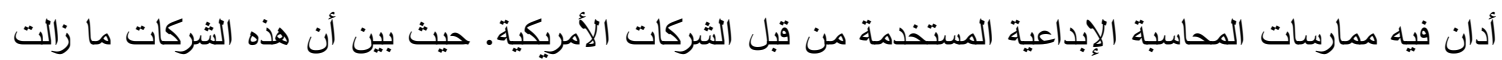

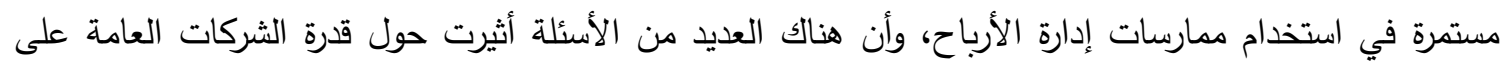

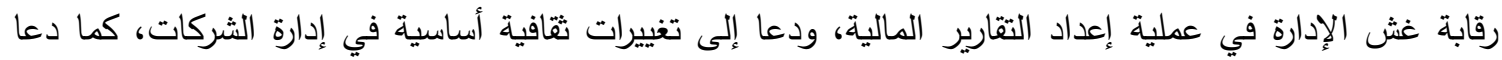
لتقوية الحوكمة المؤسسية من خلال تحسين فعالية لجان التدقيق وتقويتها وأن تكون أكثر يقظة وحرصاً في أداء وظائفها الإشرافية، بالإضافة إلى ممارسة دور رقابة أكبر وإلى الحذر من عمليات إعداد التقارير المالية المحرفة .(Levitt, 1998) ومن الواضح أن القطاع الخاص في فلسطين يعاني كثيراً من ضعف مستوى الحوكمة في المؤسسات ذات العلاقة به، ومن هذه المظاهر الركود في الغرف التجارية، ومحدودية عدد الشركات الفلسطينية المدرجة في بورصة فئس

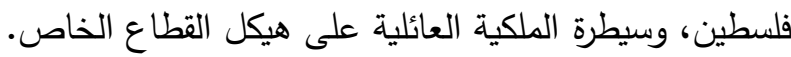

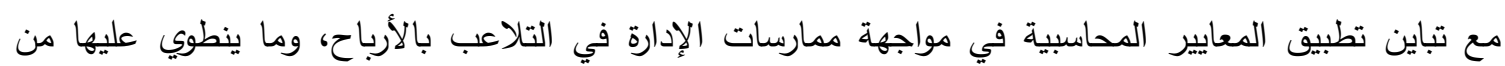

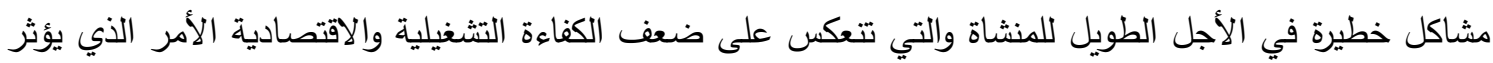

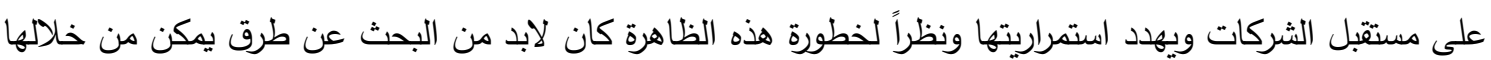

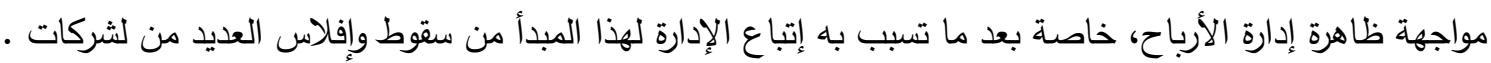
وعليه فإن صياغة مشكلة الاراسة تتمثل في السؤال الرئيس التالي: 


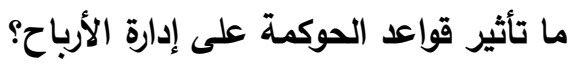
ويتفرع من السؤال الرئيسي الأسئلة الفرعية التالية:

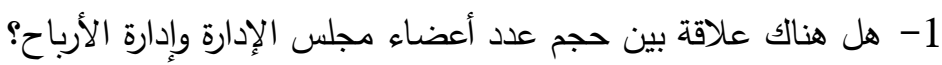

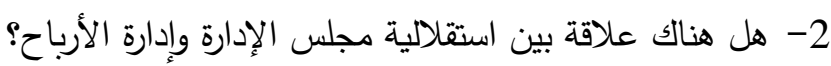

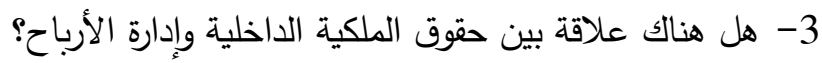
4- هل هناك علاقة بين تولي المدير التتفيذي للشركة لمنصب رئيس ولئ مجلس الإدارة وإدارة الأرباح؟

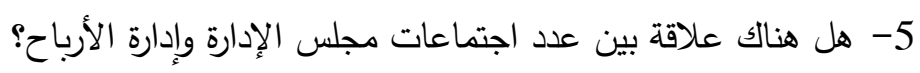

أهداف الدراسة: بناء على مشكلة الدراسة يمكن تحديد الأهداف على النحو التالي: 1- الكثف عن العلاقة بين حجم مجلس الإدارة وإدارة الأرباح. 2- بيان العلاقة بين استقلالية مجلس الإدارة وإدارة الأرباح. 3- التعرف على العلاقة بين حقوق الملكية الداخلية وإدارة الأرباح. 4- بيان ما إذا كان هناك علاقة بين تولي المدير التتفيذي للشركة لمنصب رئيس مجلس الإدارة وإدارة الأرباح 5- بيان ما إذا كان هناك علاقة بين عدد اجتماعات مجلس الإدارة وإدارة الأرباح

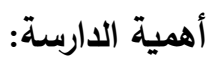
إن التطبيق الفاعل لحوكمة الثركات يساهم في الكثف عن الممارسات الخاطئة في ممارسة إدارة الأرباح في الثركات المدرجة أسهمها في بورصة فلسطين للأوراق المالية. إذاً فأهمية الاراسة تتمثل في أنها: 1- تتناول قطاعاً مهماً ألا وهو قطاع الثركات الصناعية والخدمية المدرجة أسههها في بورصة فلسطين التي تمثل عصب الحياة المالية والاقتصادية في الاقتصاد الفلسطيني. 2- تكثف الدراسة عن ممارسات إدارة الأرباح في الثركات الصناعية والخدمية المدرجة أسهها في بورصة

$$
\text { فلسطين. }
$$

3- تساعد المراقبين والمختصين في مجال الحسابات من الاستفادة من نتائجها. 4- تساعد المهتمين في مجال المحاسبة في الاستفادة من الأساليب الإحصائية المستخدمة في هذه الدراسة. 5- تمثل إضافة للمكتبة الفلسطينية حيث أن الكتابات في هذا الموضوع فئغاده من اليلة جدا.

فرضيات الدراسة:

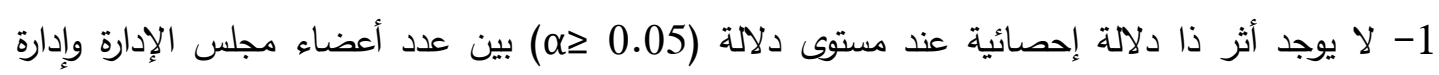

$$
\text { الأرباح؟ }
$$

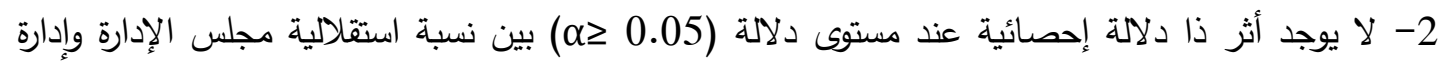

$$
\text { الأرباح? }
$$

3- لا يوجد أثر ذا دلالة إحصائية عند مستوى دلالة (1) (م) بين عدد اجتماعات مجلس الإدارة وإدارة

$$
\text { الأرباح؟ }
$$


4- لا يوجد أثر ذا دلالة إحصائية عند مستوى دلالة (م20.05) بين ازدواجية منصب المدير التتفيذي وإدارة الأرباح؟

5- لا يوجد أثر ذا دلالة إحصائية عند مستوى دلالة (م20.05) بين نسبة حقوق الملكية الداخلية وإدارة الأرباح؟

$$
\text { متغيرات الدراسة: }
$$

سوف يتم تطبيق نموذج (Jones) المعدل (1995) وذلك بهدف قياس وتقدير إدارة الأرباح المتمثلة في قيمة المستحقات الاختيارية في الثركات موضوع الدراسة، حيث يهدف هذا النموذج إلى التصدي للتأثيرات الناتجة

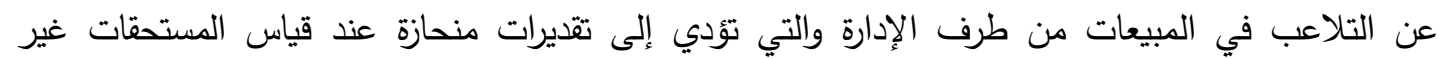

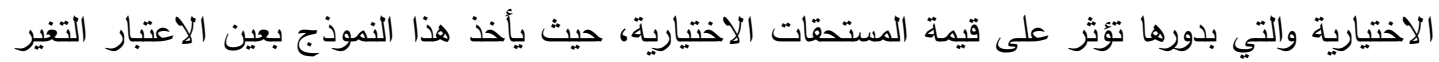
الحاصل في المبيعات النقدية كعنصر غير معرض للتلاعب بدلاً من التغيرات الحاصلة في رقم الأعمال. ويمكن صياغة نموذج (Jones) المعدل كما يلي: NDACit $/$ Ait-1 = a0 + 1 1 (1 / Ait-1) + $22[(\Delta$ REVit $-\Delta$ RECijt) / Ait-1] + 33 (PPEit ( Ait-1)

حيث أن:

$$
\begin{aligned}
& \text { t المستحقات غير الاختيارية للشركة (i) خلال الفترة NDACit } \\
& \text { AREVit }
\end{aligned}
$$$$
\text { SRECit }
$$$$
\text { PPEit }
$$

مع معالم النموذج الخاصة بالشركة يتم تقديرها لمجموعة شركات العينة، وذلك لكل سنة من

$$
\text { سنوات الدراسة. }
$$

وسيتم قياس قواعد الحوكمة في هذه الدراسة من خلال (حجم عدد أعضاء مجلس الإدارة، استقلالية مجلس الإدارة،

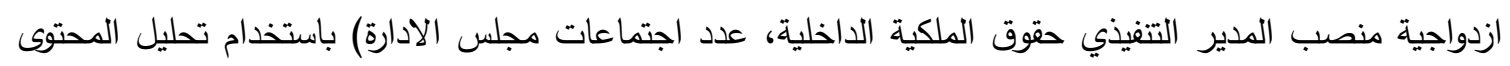
للنظام الأساسي للشركات موضع الدراسة.

$$
\text { 2. }
$$

وسيتم قياس قواعد الحوكمة من خلال الأدوات التالية:

• حجم مجلس الإدارة: سيتم قياسه من خلال عدد أعضاء مجلس الإدارة.

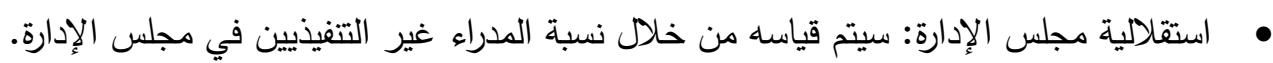

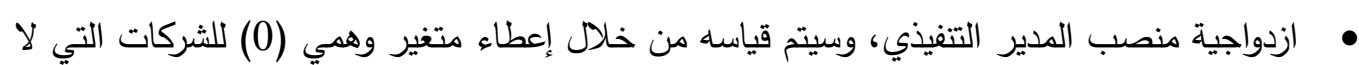

يوجد بها ازدواجية، ورقم (1) للشركات التي يوجد بها ازدواجية في المنصبين.

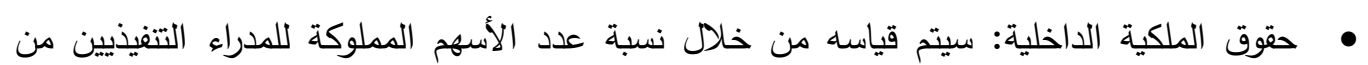

$$
\text { إجمالي رأسمال الشركة. }
$$

• عدد اجتماعات مجلس الإدارة: سيتم قياسه من خلال عدد اجتماعات مجلس الإدارة. 
وذلك بالاستتاد إلى البيانات المنشورة في التقارير الإدارية والمالية للشركات موضوع الدراسة.

نموذج الدراسة:

المتغير التابع

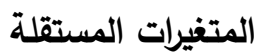

109
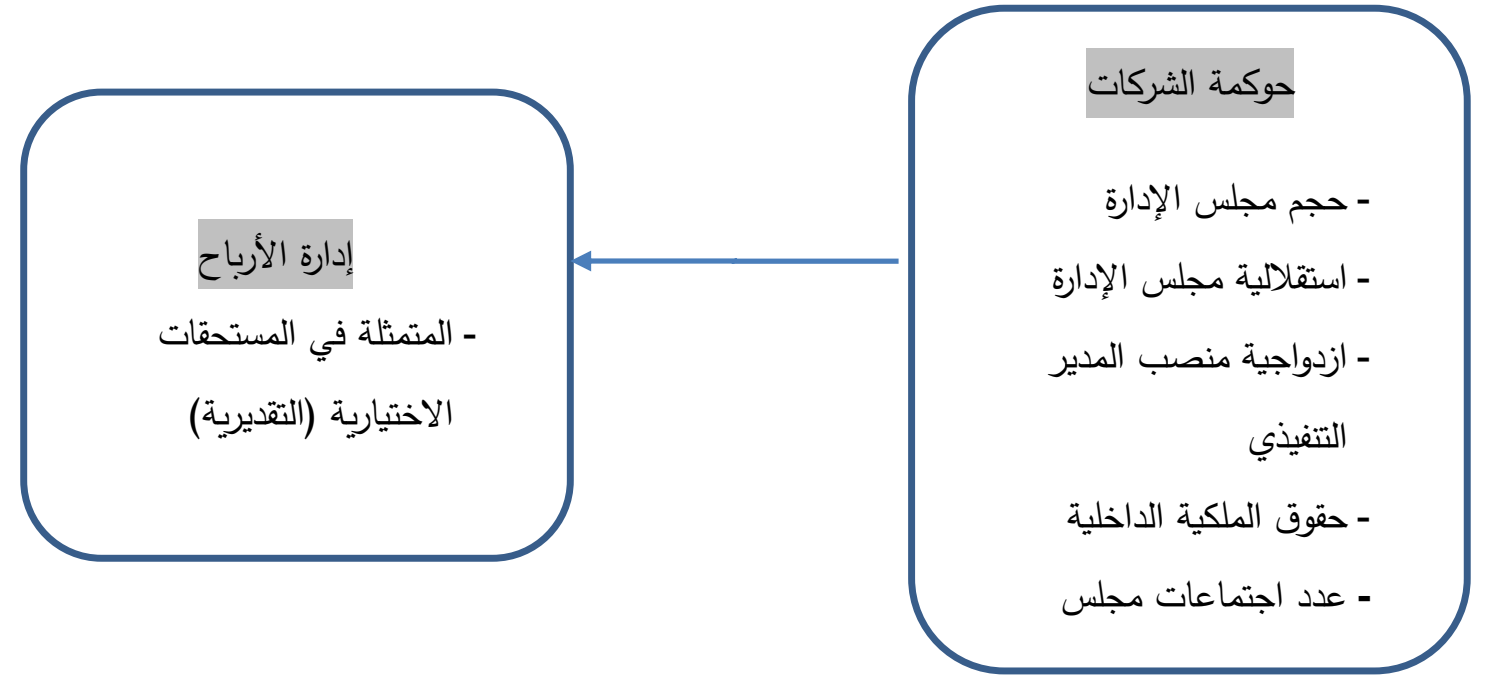

مصطلحات الاراسة:

1

مجموعة من القواعد والممارسات والضوابط الرقابية التي تهدف إلى ضمان قيام الإدارة باستخدام أصول الشركة المادية والمعنوية بأمانة لمصلحة المساهمين، أو تمكين المساهين وغيرهم من ذوي المصالح بالثركة من ممارسة حقوقهم وحماية مصالحهم" (يوسف، 2007: 7 )

قامت مؤسسة التمويل الدولية FCC ابتعريف الحوكمة بأنها "هي النظام الذي يتم من خلاله إدارة الثركات والتحكم في أعمالها. (Alamgir, 2007) وعرفها البنك الدولي (1992) الحكم الراشد مرادف التسيير الاقتصادي الفعال والأمثل.

الذي يسعى للإجابة عن مختلف الانتقادات الخاطئة، والموجهة للدول والمؤسسات التي تثثك

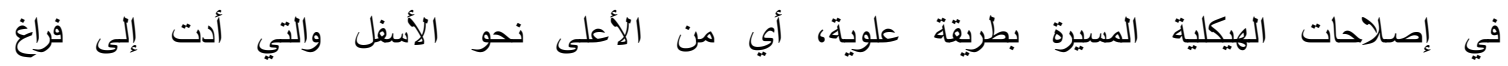

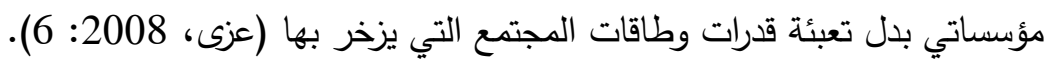

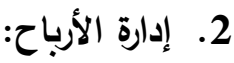

تعرف بأنها "تدخل متعمد في عملية إعداد التقارير المالية الخارجية بنية تحقيق بعض المكاسب الخاصة

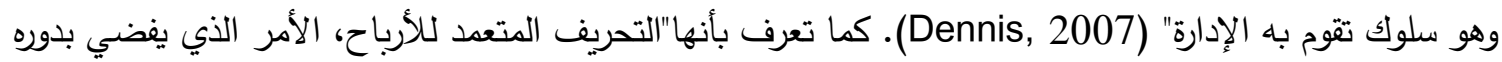
إلى أرقام محاسبية تختلف بشكل أساسي عما يمكن أن تكون عليه في غياب التلاعب، وذلك عندما يتخذ المديرون قرارات لا تخضع لأسباب استراتيجية بل لمجرد التعديل على الأرباح". Bedard, 1991; Alareeni and (Branson, 2019; Alareeni, 2014, Alareeni, 2013 
الاطار النظري والدراسات السابقة

نشأة حوكمة الثركات:

بدأ الحديث عن الحوكمة بوضوح مع بداية عام (1999)، بعد تراكم نتائج دراسات حول إخفاق شركات ومؤسسات

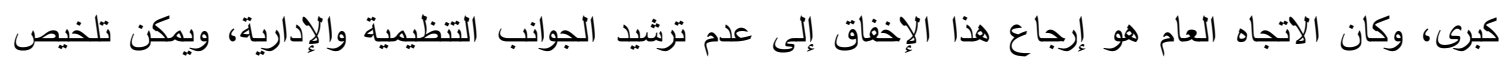

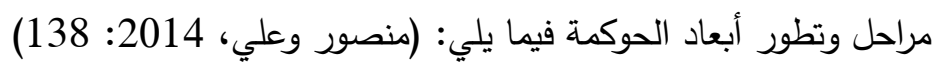

- - - حقبة الركود (ما بعد عام 1932)، بدأ الاقرار بعمق الفجوة بين الإدارة والمالكين، واختلاف المصالح. - حقبة ظهور نظرية الوكالة وضبط العلاقة (1976-1995)، حيث تم ظهور الادبيات بشأن ضبط وتتظيم

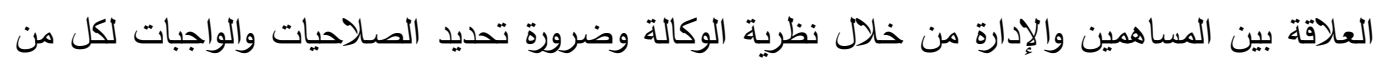

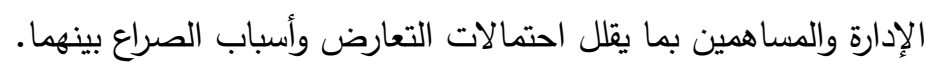

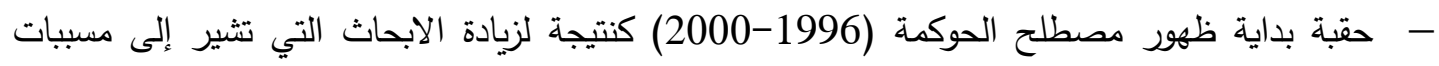

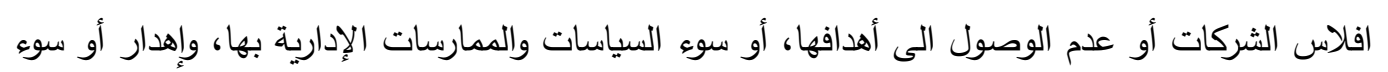

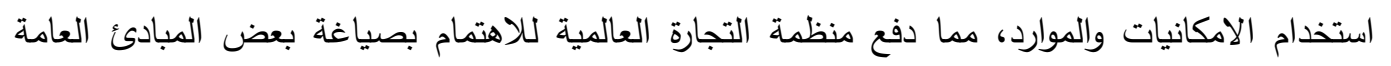
للحوكمة التي يفترض أن تراعيها الثركات بالدول النامية، ثم تبعها إصدار المنظمة العالمية للتعاون الاقتصادي والتتمية لمجموعة من المبادئ العامة للحوكمة.

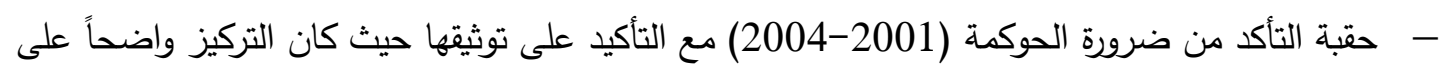
حالات الفثل والفساد الأخلاقي والقيمي في العديد من الممارسات المالية والاستثمارية في كثير من من القطاعات.

يرى الباحث أن الحوكمة مرت بعدة مراحل وتطورات، حيث ظهرت الكثير من الشواهد التي تؤكد على ضرورة وجود

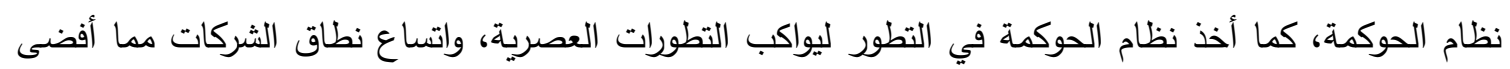

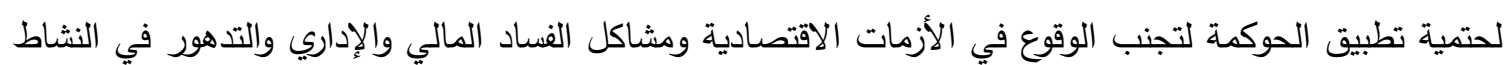
الاقتصادي.

\section{مفهوم حوكمة الثركات: تعرف حوكمة الشركات بأنها:}

أداة تمكن إدارة الشركة من تحقيق أهدافها على المدى البعيد بطريقة تحمي حقوق ذوي المصالح، فمهوم حوكمة

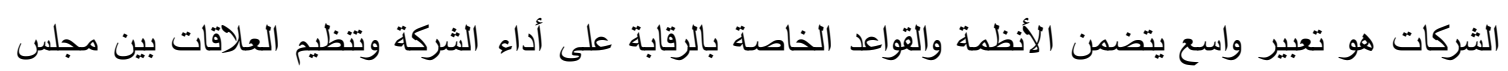
الإدارة والمديرين والمساهمين وأصحاب المصالح الأخرى. (قويدر، 2015: 15). كما عرفت الحوكير الحوكمة "بأنها مجموعة من القواعد والممارسات والضوابط الرقابية التي تهدف إلى ضمان قيام الإدارة باستخدام أصول الثركين

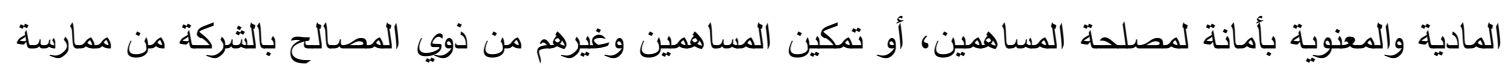

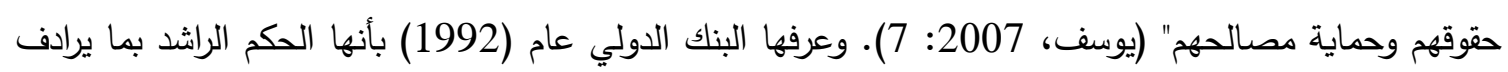
التسيير الاقتصادي الفعال والأمثل الذي يسعى للإجابة عن مختلف الانتقادات الخاطئة، والموجهة للدول والمؤسسات التي تثكك في إصلاحات الهيكلية المسيرة بطريقة علوية، أي من الأعلى نحو الأسفل والتي أدت إلى فراغ 
مؤسساتي بدل تعبئة قدرات وطاقات المجتمع التي يزخر بها (عزى، 2008: 7). يمكن أيضاً تعريفها بأنها "القوانين

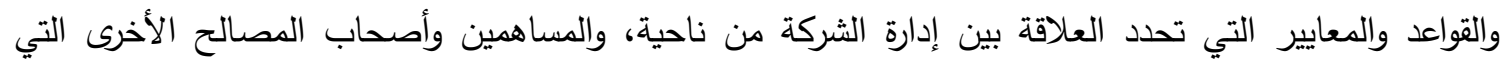
تربطهم علاقة بالشركة مثل البنوك، والموردين. (4aidar, 2009). من المنظور المحاسبي يشير الففهوم

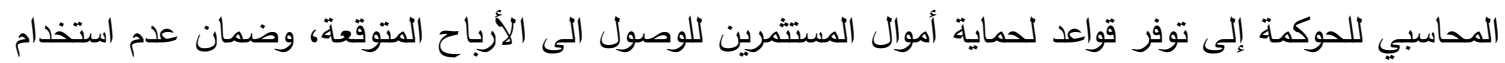
هذه الأموال في مجالات أخرى أو استثمارات ذات خطورة مرتفعة وعدم استغلالها من قبل الإدارة لتحقيق منافع شخصية، ويتم ذلك من خلال مجموعة الإجراءات والضوابط والمعايير المحاسبية، وتركز هذه النظرية على تحقيق الثفافية وتوسيع نطاق الإفصاح عن البيانات المحاسبية والقوائم المالية ومزايا المديرين وتطبيق المعايير الدحاسبية

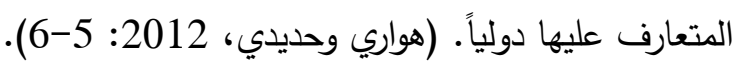

خصائص الحوكمة: حوكمة الشركات تتميز بعدة خصائص، ومن بين خصائصها نذكر منها: (حمودي، 2015: 43-44)، (الكايد، (115:2003 أولاًَ-الإفصاح والثفافية: وهي دعامة هامة لضمان النزاهة والعدالة في عمل إدارة الثركات وإدارة موظفيها واتخاذ القرارات الصائبة، حيث تضمن خاصية الإفصاح والثفافية تحويل معلومات صحيحة وواضحة عن أداء الثركات عن طريق توفير نظام فعال للتقارير يتسم بالثفافية للإدارة والمساهمين فحسب، بل لكل الجهات ذات الصلة، وكذلك التركيز على حرية تدفق المعلومات، بحيث تكون في متتاول جميع المعنيين بها.

ثانياً-(المساءلة: هي قاعدة تقضي بمحاسبة المسئولين أو متخذي القرارات والذين يقومون بتتفيذ الأعمال في الثركة المناطة بهم، فهم الأطراف الخاضعة للمساءلة المحاسبية عند تطبيق الحوكمة أمام أصحاب المصالح، وكذلك تركز على مسئوليات القيادات ومتخذي القرارات أمام المستفيدين والمجتمع وكل من يهمه الأمر .

ثالثاً -المسؤولية: تكون المسؤولية الأساسية للحوكمة الجيدة متروكة للمديرين والمدققين وتزويد المساهمين بضمان موضوعي ومستقل بالاعتماد على التقارير المالية والمعلومات الأخرى المقدمة من الثركة، إن هذا الدور الحيوي يبرد الدئه الموقع الخاص للمدققين تحت قانون الشركات. رابعاً-تحقيق العدالة والإنصاف:

وهي الاحترام والاعتراف بحقوق كل الأطراف ذات المصالح ومن بين هذه الأطراف مصالح أقلية المساهمين، وكذلك ترتكز على توفير الفرص للجميع لتحسين أوضاعهم أو الحفاظ عليها.

خامساً--المشاركة: ترتكز على أن المشاركة في اتخاذ القرار حق للجميع ولا يجوز لشخص أو فئة التقرد به. أهمية ومزايا الحوكمة: إن للحوكمة الكثير من المزايا التي تدعمها بالثكل الذي تسعى معظم المنشآت بل والدول إلى تطبيقها ووضع

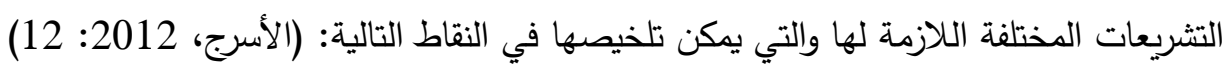


- تحسين القدرة التتافسية للمنثآت وزيادة قيمتها. - فرض الرقابة الفعالة على أداء المنشآت وتدعيم المساءلة المحاسبية بهاد فئهات - ضمان مراجعة الأداء التثغيلي والمالي والنقدي للمنشآت.

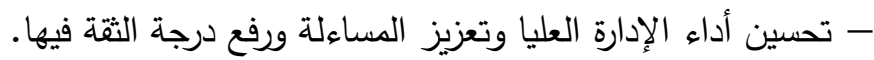
- تعميق ثقافة الالتزام بالقوانين والمبادئ والمعايير المتقق عليها.

$$
\text { - - تعظيم أرباح الثركة. }
$$

- الحصول على التمويل المناسب والتتبؤ بالمخاطر المتوقعة. - تحقيق العدالة والثفافية ومحاربة الفساد. - مراعاة مصالح الأطراف المختلفة وتفعيل التواصل معهم.

\section{أهداف الحوكمة}

يساعد الأسلوب الجيد لحوكمة الثركات على دعم الأداء الاقتصادي، والقدرة التتافسية وجلب الاستثمارات للشركات

والاقتصاد بشكل عام، وتحقق حوكمة الشركات الجيدة العديد من الأهداف، ومن أهمها: (كأنه، 2014: أ- محاربة الفساد بكل صوره سواءً كان فساداً مالياً أم محاسبياً أم سياسياً. ب-جذب الاستثمارات سواء الأجنبية أو المحلية والحد من هروب رؤوس الأموال. ج-تحقيق الاستقرار والمصداقية للقطاعات المالية على المستوى المحلي والدولي. د- دعم عنصر الثفافية في جميع معاملات وعمليات الثركات وإجراءات المحاسبة والتدقيق المالية بالصورة الذي تمكن من ضبط عناصر الانحراف في أي مرحلة.

هـ - تحسين وتطوير إدارة الشركات ومساعدة الإدارة العليا على بناء إستراتيجية سليمة بحيث تضمن اتخاذ

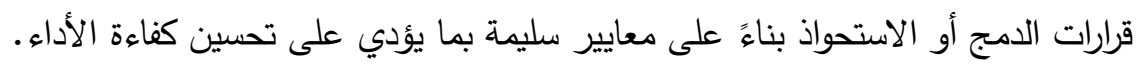
و - تحقيق إمكانية المنافسة في الأجل الطويل وهذا يؤدي إلى خلق حوافز للتطوير وتبني تكنولوجيا حديثة لزيادة درجة جودة المنتجات وتخفيض التكاليف الإنتاجية وزيادة القابلية التسويقية للسلع والخدمات التي تتعامل فيها الشركة حتى تتمكن من الصمود أمام المنافسة القوية للمنتجات الأجنبية. ز - تعزيز الثقة في الاقتصاد القومي وترسيخ دور سوق المال ورفع قدرته على تتمية المدخرات وزيادة معدلات الاستثمار من ناحية وتثجيع نمو القطاع الخاص ودعم القدرة التتافسية من ناحية أخرى.

ح-ضمان وجود هياكل إدارية يمكن معها محاسبة إدارة الشركة أمام مساهيها مع ضمان وجود المراجعة المستقلة على المديرين والمحاسبين وصولاً إلى قوائم مالية ختامية على أساس مبادئ محاسبية عالية مدادية

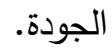

ط-ضمان مراجعة الأداء المالي وحسن استخدام أموال الثركة ومدى الالتزام بالقانون والإثراف على

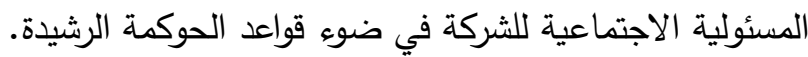

ي -تعميق شفافية الالتزام بالمبادئ والمعايير المتقق عليها وخلق أنظمة للرقابة الذاتية ضمن إطار أخلاقي نابع من العمل والأخلاق السائدة في المجتمع رآداب...................... ومبادئه. 
وفي ضوء ما سبق، يرى الباحث أن الحوكمة تهدف إلى تحقيق الثفافية والعمل على تفعيل نظام الرقابة الداخلية

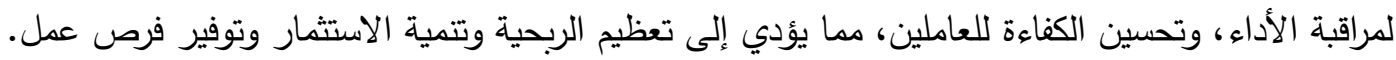

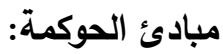

من أجل بناء نظام سليم للحوكمة أو إصلاح نظام حوكمة قائم، عملت منظمة التعاون الاقتصادي والتتمية (OECD)

مرجعيات للاستعانة والاسترشاد بها والتي يمكن تلخيصها فيما يلي: (Freeland, 2007: 23) - - - ضمان وجود أساس لإطار فعال لحوكمة الشركات: يعمل على رفع شفافية وكفاءة الأسواق وأن يكون متوافقً مع حكم القوانين وأن يحدد بصوره واضحة توزيع المسئوليات بين كافة الجهات الإشرافية والتنظيمية والتنفيذية. - - حقوق المساهمين: ينبغي أن يكفل إطار معايير ممارسة الحوكمة في الشركات حماية حقوق المساهين، ويجب أن يكون المساهمين على دراية كاملة بما يجري داخل الثركة وأن يكون لديهم قدرة كاملة على فهم واستيعاب كافة النواحي الخاصة بالقوائم المالية المتعلقة بعدم المساس بحقوقهم وعلى مصالحهم الخاصة.

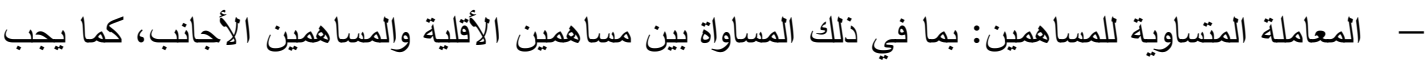
أن يتم معاملة المساهمون المنتمون إلى فئة واحدة نفس المعاملة المتساوية.

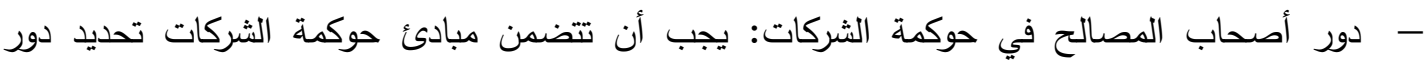
أصحاب المصالح من موردين ومقرضين وموظفين ومستهلكين وغيرهم، كما يحددها القانون واحترام الحقوق القانونية لأصحاب المصالح وإتاحة التعويضات عن أية خروج عن تلك الحقوق، وتحفيز التعاون بين الشركات وأصحاب المصالح الأخرى. - - الإفصاح والثنفافية: بحيث ينبغي الإفصاح بكفاءة وفاعلية في الوقت المناسب عن جميع الموضوعات الهامة المتعلقة بالثركة بما في ذلك المركز المالي وتطور الأداء وبيانات حقوق الملكية وكبار المساهمين وكذلك وجود مراجعة خارجية مستقلة بواسطة مراجع كفه ومستقل. - مسئولية مجلس الإدارة، يجب أن تتضمن مبادئ حوكمة الشركات مسئوليات مجلس الإدارة وبحيث تكون محددة وواضحة ومعلن عنها سواء من جانب الصلاحيات والمسئوليات والحقوق والواجبات والمزايا والبدلات والأجور والمكافآت، ومن أهم مسئوليات المجلس مراجعة وتوجيه إستراتيجية الثركة ووضع

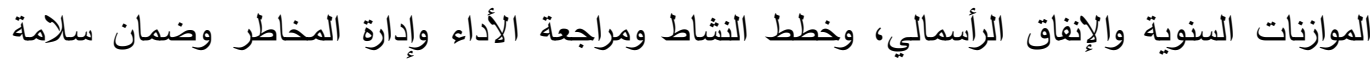
التقارير المحاسبية والمالية للشركة.

الحوكمة في فلسطين: لقد أدخلت منشآت القطاع الخاص في معظم الدول العربية الدفاهيم الحديثة في حوكمة الثركات وذلك لإدراكها

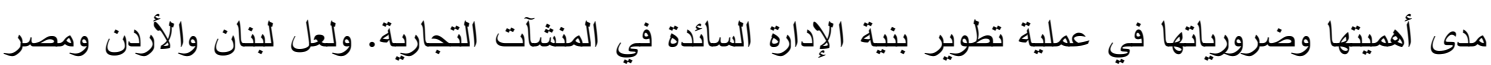

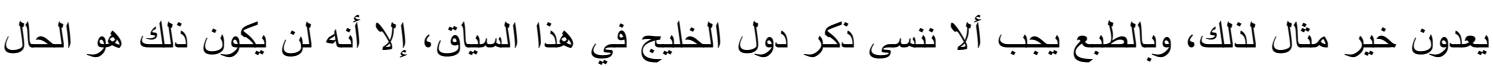
في مناطق الضفة الغربية وقطاع غزة حيث كانت عملية التطوير في بنية الإدارة السائدة في المنشآت التجارية بطيء جداً بشكل يلفت الأنظار سواء كان ذلك خلال فترة الاحتلال أو حتى بعد إقامة السلطة الوطنية الفلسطينية (عورتاني وموسى، 2003: 6) ولتلافي القصور في التظيم القانوني لمبادئ حوكمة الشركات في التشريعات ذات 
الصلة بالحوكمة بالسارية في فلسطين، مثل قانون الثركات الأردني رقم 12لسنة 1964م، الساري المفعول في الضفة الغربية، وقانون الشركات رقم 22 لسنة 1929 الذي كان ساري المفعول في قطاع غزة قبل إصدار قانون

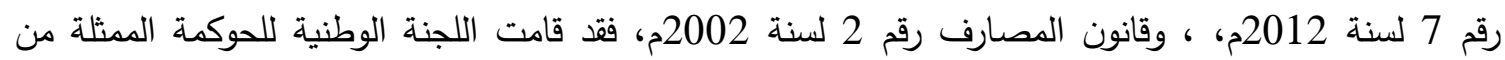
13مؤسسة، من بينها: (هيئة سوق رأس المال الفلسطينية، والسوق المالي، ومراقب الشركات، وسلطة النقد الفلسطينية، وجمعية البنوك، وجمعية رجال الأعمال، والمجلس التتسيقي لمؤسسات القطاع العام، والاتحاد العام لشركات التأمين، ومدققي الحسابات والمحامون، وأكاديميون) في شباط من العام ،

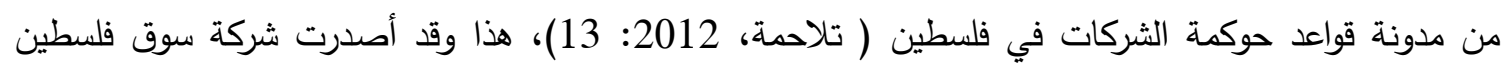
للأوراق المالية في أغسطس عام 2016م دليلاً لحوكمة الشركات لتشجيع الشركات المدرجة في بورصة فلسطين على اتباع الممارسات الفضلى لحوكمة الشركات. حيث إن تطبيق الحوكمة مهماً جداً للدول النامية ذات الموارد المحدودة عمن سواها، وذلك بسبب ارتباطها بالقدرة على اجتذاب الاستثمارات الأجنبية الضرورية للتمية، لذا فقد وجب العمل على تحسين جودة الحوكمة في فلسطين

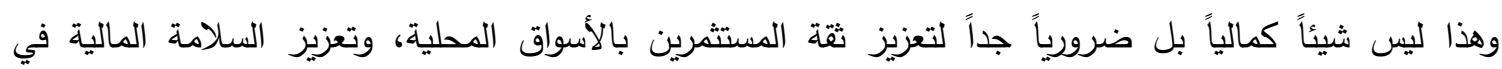

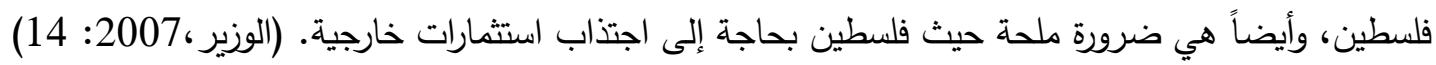

النماذج المستخدمة في اكتثاف ممارسات إدارة الأرباح:

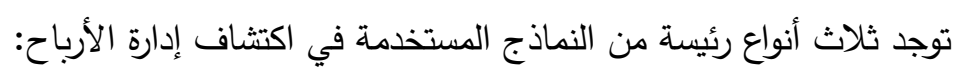

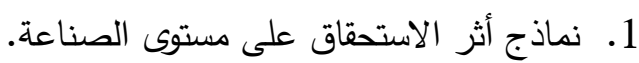
2. نماذج تحليل توزيعات الأرباح.

3. نماذج ركزت على احتساب الاستحقاق الإجمالي وتفريقه بين إجباري واختياري. ( McNichols,

أولا: نموذج أثر استحقاق الصناعة: يفترض نموذج الصناعة، والمطور من قبل (Dechow and Sloan, 1991)، (Petroni, 1992)، تمتع جميع الشركات في نفس الصناعة بنفس مصادر التغير في أثر الاستحقاق الاجمالي (McNichols, 1998) لذات الصناعة، حيث يعتمد نموذج (Dechow and Sloan) على إجراء تحليل الانحدار لأثر الاستحقاق غير الأني الاختياري كدالة في متوسط أثر الاستحقاق الاجمالي للصناعة، وتتمثل الميزة الأساسية لنموذج اثر استحقاق الثاء الصناعة في أنه يمكن بسهولة التمييز بين أثر الاستحقاق الاختياري وغير الاختياري، ويمكن الاعتماد على الإئى

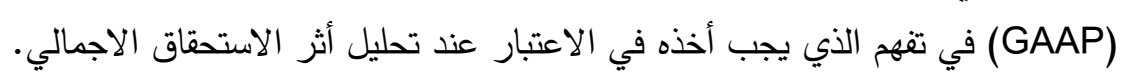

ثانياً: نماذج تحليل شكل توزيع الأرباح: قدمت دراسة (Burgstahler and Dichev, 1997) طريقة أخرى لاكتثاف ممارسات إدارة الأرباح، وهي طريقة توزيع القطاع العرضي للأرباح (Cross-Sectional Distributional Method) حيث تستخدم تلك الطريقة بشكل واسع في اكتشاف ممارسات إدارة الأرباح حول المؤشرات القياسية الأساسية للأرباح مثل الأرباح الصغرية، وأرباح السنة السابقة، وتوقعات المحليين الماليين، وتتمثل الميزة الأساسية لنموذج تحليل شكل توزيع الأرباح في أنها تمكن الباحث من التتبؤ بمعدل تكرار حدوث الأرباح المحتمل أن تكون ناتجة عن الأرباح الاختيارية. 
يعتمد مدخل تحليل شكل توزيع الأرباح لاكتشاف إدارة الأرباح على فحص التوزيع التكراري للقطاع العرضي للأرباح بهدف التحقق مما إذا كانت أرباح الشركات تتوزع بشكل منظم على نقاط تقع مباشرة أعلى أو أسفل المؤشرات

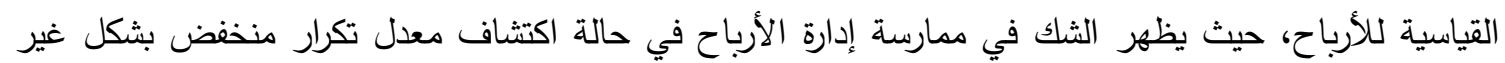

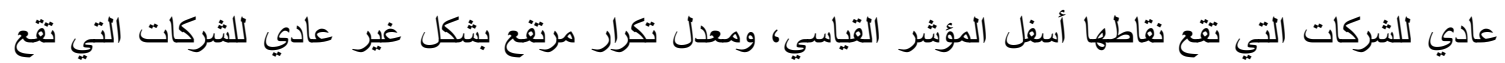

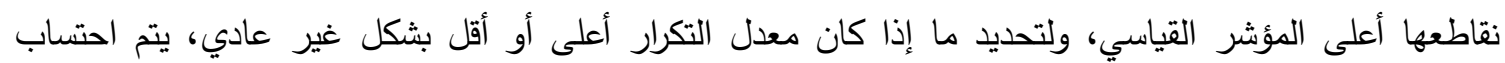

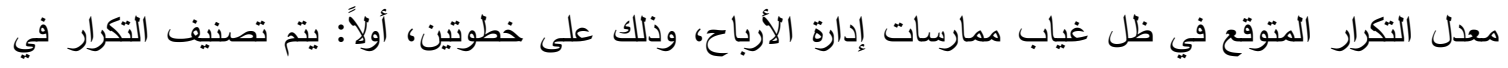

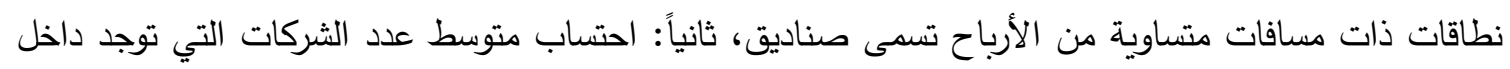

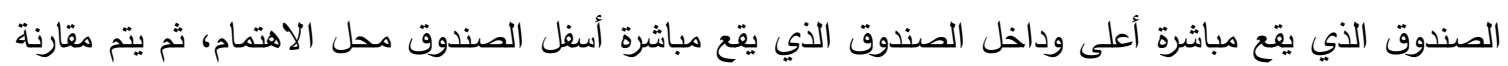

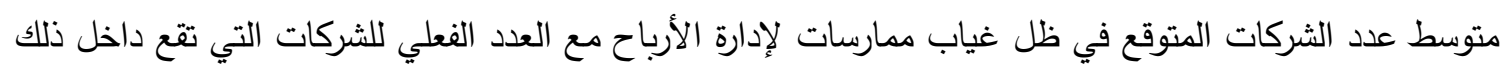

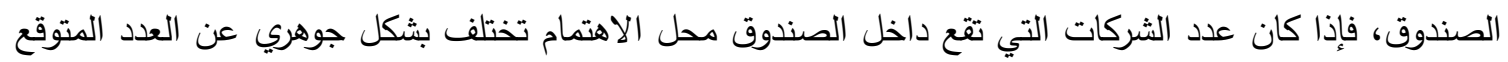
للشركات، إذن يتوقع وجود ممارسات لإدارة الأرباح. (Burgstahler \& Dichev, 1997)

ثالثاً: نماذج ركزت على احتساب الاستحقاق الإجمالي وتقسيمه إلى اختياري وإجباري:

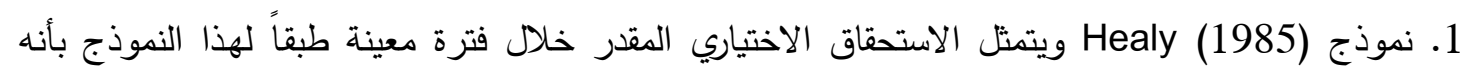

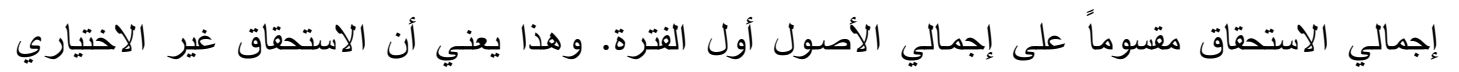

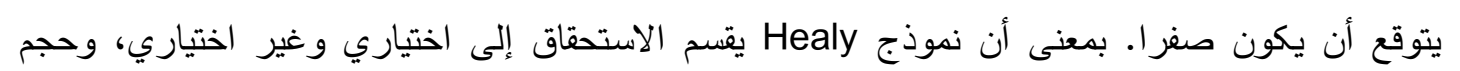

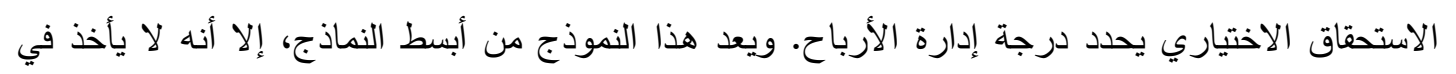

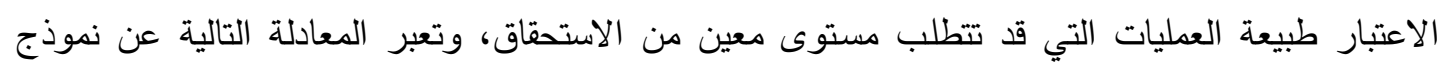

Healy.

\section{EDACit $=$ TACit $/$ Ait -1}

\section{Where:}

EDACit $=$ Estimated discretionary accruals for firm $\mathrm{i}$ in year $\mathrm{t}$. TACit $=$ Total accruals for firm $i$ at the beginning of year $t$.

Ait $-1=$ Total assets for firm $i$ at the beginning of year $t$. " $\mathrm{i}$ " refers to the firm or the industry depending on whether the analysis is time series or cross - sectional

2. نموذج (1986) يختبر هذا النموذج إدارة الأرباح عن طريق حساب الاختلافات بين اجمالي

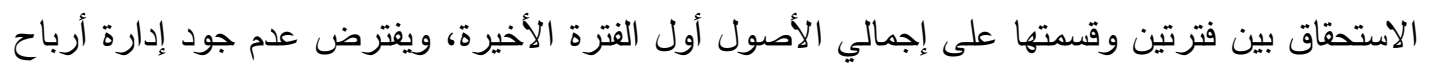

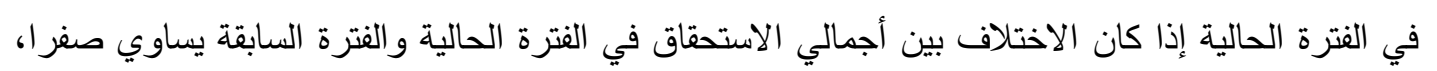

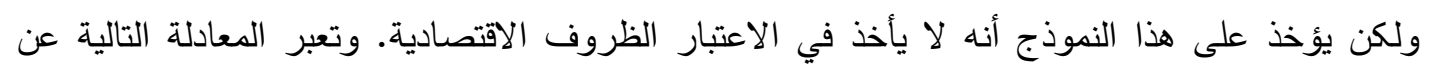

\section{EDACit $=$ TACit - TACit $-1 /$ Ait -1}

\section{Where:}


DACit $=$ Estimated discretionary accruals for firm $\mathrm{i}$ in year $\mathrm{t}$. TACit $=$ Total accruals for firm $i$ at the beginning of year $t$.

Ait -1 Total assets for firm $i$ at the beginning of year $t$. " $i$ " refers to the firm or the industry depending on whether the analysis is time series or cross - sectional.

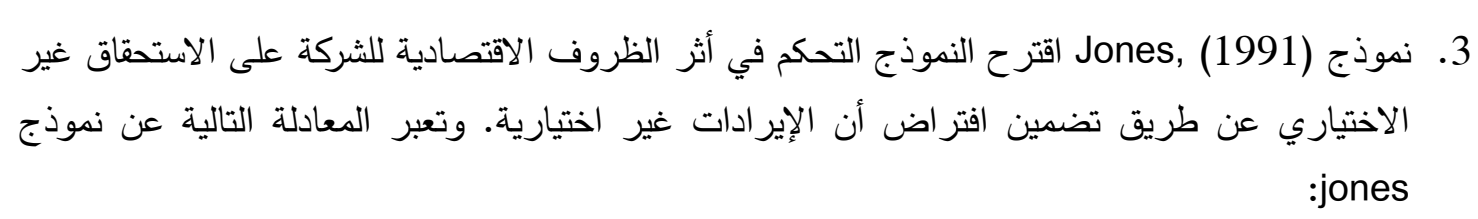

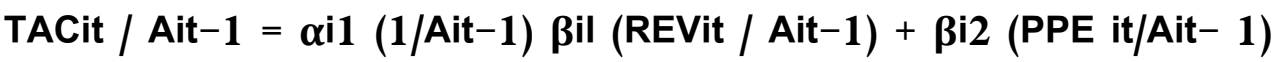

$+€ \mu$

\section{Where:}

TACit $=$ Total Accruals for firm $\mathrm{i}$ in year $\mathrm{t}$.

Ait $-1=$ Total Assets for firm $\mathrm{I}$ at the beginning of year $\mathrm{t}$.

$\mathrm{REVit}=$ change in revenue for firm if from year $\mathrm{t}-1$ to year $\mathrm{t}$.

PPE it $=$ Gross property, plant, and equipment for firm $\mathrm{i}$ in year $\mathrm{t}$.

All variables are deflated by beginning total assets to adjust for heteroscedasticity.

4- نموذج (1995) Dechow, et al. وهو نسخة معدلة لنموذج Jones حيث تتاول النموذج قضية التحكم في الإيرادات وعلاقته بإدارة الأرباح، ويفترض النموذج ضمنا أن كل التغيرات في المبيعات الآجلة خلال فترة

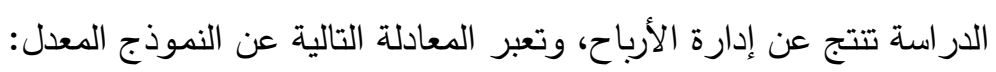

\section{EDACit = TACit / Ait-1 - \{ ail ( 1 / Ait-1) + bil (( REVit _ ARit)/Ait-1)+bi2} (PPEit/Ait-1)\}

Where:

EDACit $=$ Estimated discretionary accruals for firm $\mathrm{i}$ in year $\mathrm{t}$.

TACit $=$ Total accruals for firm $i$ at the beginning of year $t$.

Ait $-1=$ Total Assets for firm $\mathrm{i}$ at the beginning of year $\mathrm{t}$,

REVit $=$ Change in revenue for firm $\mathrm{i}$ from year $\mathrm{t}-1$ to year $\mathrm{t}$.

$A R i t=$ Change in accounts receivable for firm $i$ from year $t-1-$ to year $t$.

PPEit $=$ Gross property, plant and equipment for firm i in year $t$.

حيث سيتم قياس إدارة الأرباح من خلال النموذج الأخير وهو نموذج جونز المعدل حسب المعادلة السابقة. 
الدراسات السابقة:

1. دراسة (Alareeni: 2018) هل حوكمة الشركات تؤثر على إدارة الأرباح في الشركات المدرجة في بورصة البحرين.

هدفت الدراسة إلى قياس مدى ممارسة الثركات في بورصة البحرين لإدارة الأرباح، وأثر حوكمة الثركات على

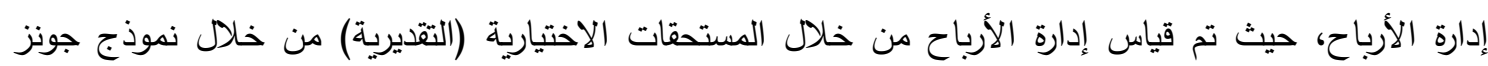

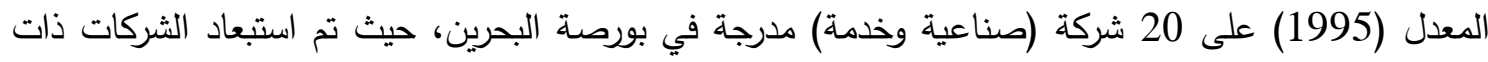
الطابع المالي وذلك لطبيعة حساباتها المختلفة عن حسابات الثركات الأخرى، وتم قياس الحوكمة من خلال (حقوق الملكية الداخلية، حجم مجلس الإدارة، ازدواجية منصب المدير التتفيذي، استقلالية مجلس الإدارة) وتوصلت الدراسة

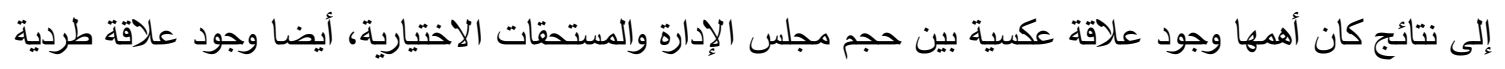

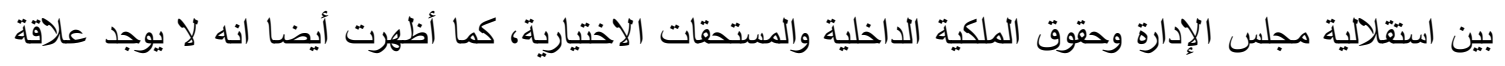
بين ازدواجية منصب المدير التتفيذي والمستحقات الاختيارية. كما أوصت الدراسة بإصدار تعديلات جديدة لتقييد ممارسات الأسواق في بورصة البحرين.

2. دراسة (ريشي: 2017) بعنوان: "دور حوكمة الثركات في الحد من سلوك إدارة الأرباح -راسة تطبيقية

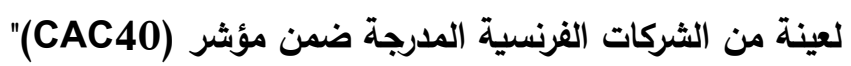
هدفت الدراسة إلى فحص دور آليات حوكمة الثركات في الحد من ممارسات إدارة الأرباح لعينة من الشركات الفرنسية المدرجة بالبورصة ضمن مؤشر (CAC40) والتي تتمثل في (19) شركة خلال الفترة (2013-2015) باستخدام نموذج الانحدار المتعدد. ولقد توصلت الدراسة إلى وجود علاقة معنوية سالبة بين كل من حجم مجلس الإدارة، استقلالية مجلس الإدارة، استقلالية لجنة التدقيق وعدد اجتماعاتها وحجم المستحقات الاختيارية، ووجود علاقة معنوية موجبة بين ازدواجية منصب المدير التنفيذي وحجم المستحقات الاختيارية، وكذلك عدم وجود علاقة

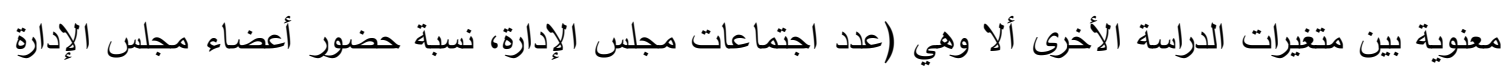

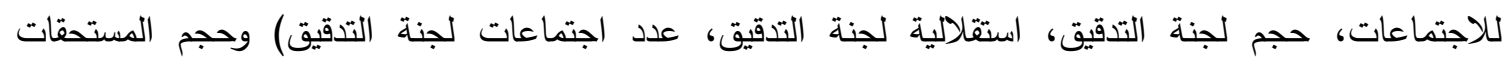

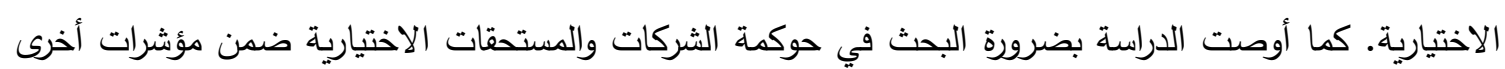
ومعايير مختلفة.

3. دراسة (Ramachandran, et.al.: 2014) بعنوان: "هل حوكمة الشركات تتؤثر على إدارة الأرباح

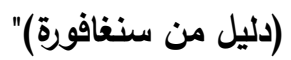

هدفت هذه الدراسة إلى دراسة العلاقة بين خصائص مجلس الإدارة وإدارة الأرباح من خلال المستحقات الاختيارية في الثركات المدرجة في بورصة سنغافورة باعتبارها دولة متقدمة من بين دول جنوب شرق آسيا وذلك باستخدام

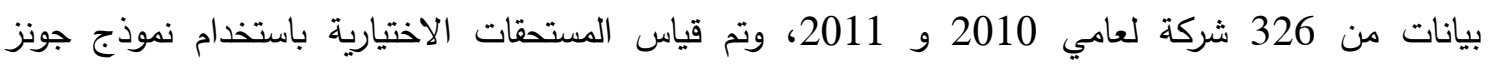

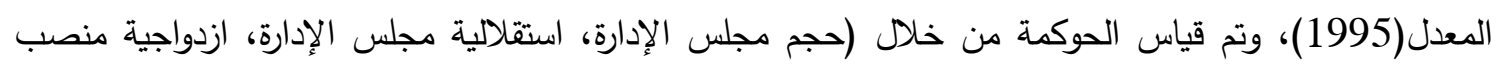
المدير التنفيذي، استقلالية لجنة المكافآت، استقلالية لجنة التعيينات). وتوصلت الدراسة إلى نتائج كان أهمها، إن فرص تسجيل المستحقات الاختيارية في الشركات المدرجة بيورصة

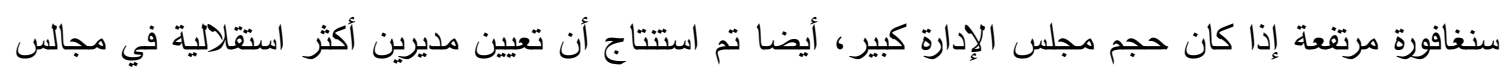
الإدارة يؤدي إلى إدارة أفضل مما يقلل من فرص تسجيل مستحقات اختيارية، أيضاً توصلت الدراسة إلى نتيجة 
مفادها أنه إذا كانت لجنة التعيينات قادرة على التأثير على لجنة المكافآت بثكل مباشر أو غير مباشر فان الدافع لتسجيل مستحقات اختيارية يكون أعلى مما يؤدي إلى زيادة إدارة الأرباح.

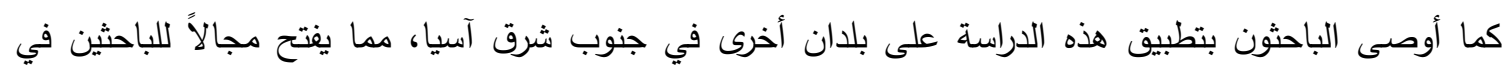
المستقبل لدراسة مدى جودة المعلومات في الإفصاحات المقدمة.

4. دراسة (الفضل وحمد: 2014) بعنوان: "حوكمة الثركات ودورها في الحد من إدارة الأرباح سـراسة اختبارية لحالة العرلق"

هدفت هذه الدراسة إلى اختبار دور عدد من الآليات الداخلية لحوكمة الشركات في الحد من ممارسات إدارة الأرباح

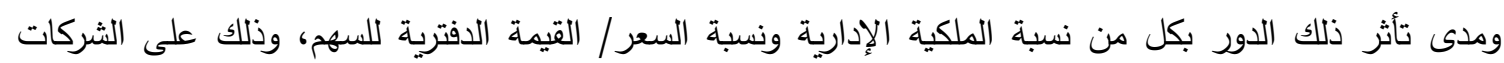

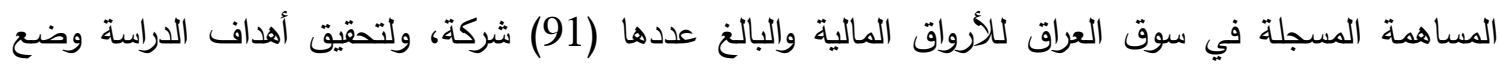
الباحث فرضيات دراسة في مجموعتين تختص المجموعة الأولى بآليات الحوكمة والمتمثلة بمجلس الإدارة ولجنة التدقيق والمراجعة الداخلية، بينما تتعلق الثانية بفحص أثر نسبة الملكية الإدارية ونسبة السعر/ القيمة الدفترية الإلية للسهم. ولقد توصلت الاراسة إلى وجود دور رقابي هام لمجلس الإدارة في ضبط ممارسات إدارة الأرباح، إذ كلما زادت كفاءة مجلس الإدارة من حيث صغر حجمه وزيادة عدد الأعضاء الخارجيين فيه كلما قلت ممارسات إدارة فارة الأرباح والعكس صحيح، وكذلك عدم وجود دور رقابي هام للجنة التدقيق في الحد من ممارسات إدارة الأرباح، وأخيراً كلما زادت جودة قسم المراجعة الداخلية في الثركة كلما زادت ممارسات إدارة الأرباح، مما يعني قيام مجلس الإدارة بتوظيف قسم المراجعة الداخلية في الشركات باتجاه ممارسات إدارة الأرباح.

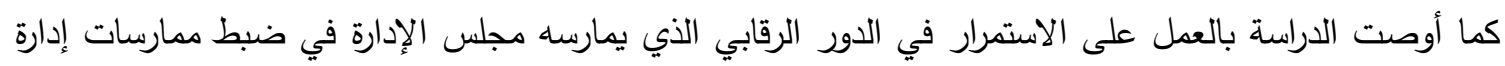
الأرباح وذلك بالإضافة لعمل لجنة التدقيق.

5. دراسة (Gonzalez and Garcia: 2012) بعنوان: "هل حوكمة الشركات تؤثر على إدارة الأرباح في

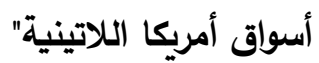

هدفت الدراسة إلى فحص العلاقة بين الآليات الداخلية لحوكمة الشركات وإدارة الأرباح من خلال قياس المستحقات الاختيارية، تم استخدام عينة من قائمة شركات أمريكا اللاتينية الغير مالية، وذلك خلال الفترة مابين عام 2006

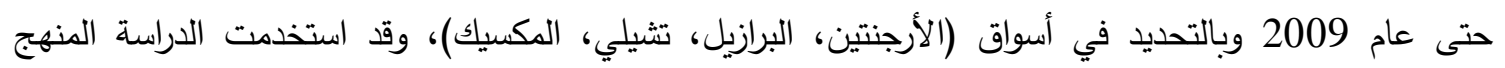

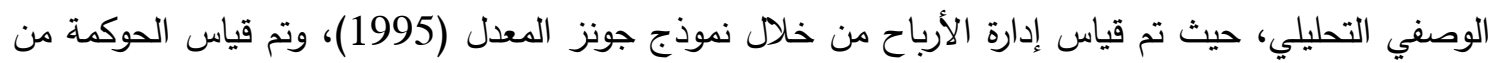
خلال الآليات الداخلية للحوكمة. وتوصلت الدراسة إلى أن بيئة تركيز الملكية المرتفعة الموجودة في شركات أمريكا

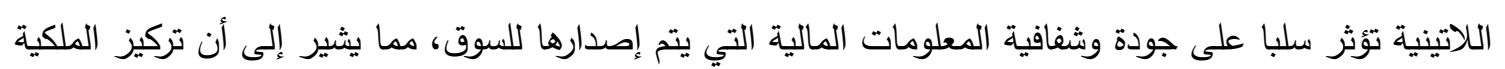
قد يكون آلية مقيدة للممارسات التلاعبية فقط عندما تكون ملكية المساهمين الرئيسين معتدلة ومعقولة، وأيضا بالمثل بالنسبة لحقوق الملكية الداخلية بإمكانها تقييد ممارسات الاستحقاقات التقديرية فقط عندما لا تكون نسبة الأسهر

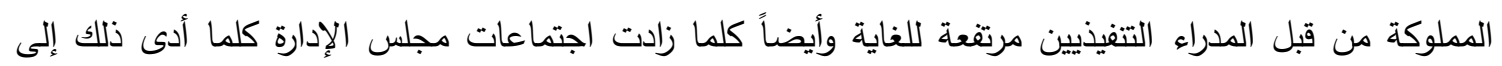
تقليل الممارسات التلاعبية المتمثلة بالمستحقات الاختيارية. كما أوصت الدراسة بضرورة تفعيل دور أسواق المال

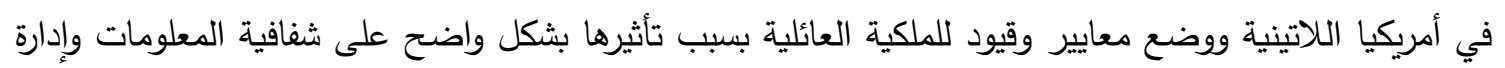
الأرباح. 
6. دراسة (المصطفى: 2012) بعنوان: "أثر حوكمة الثركات على ممارسة إدارة الأرباح -راسة تطبيقية على الثركات الصناعية المدرجة في سوق عمان المالي" الموان:

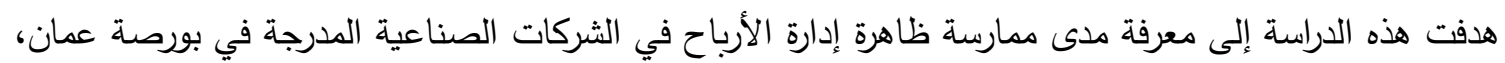

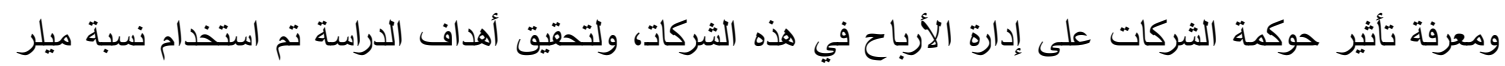

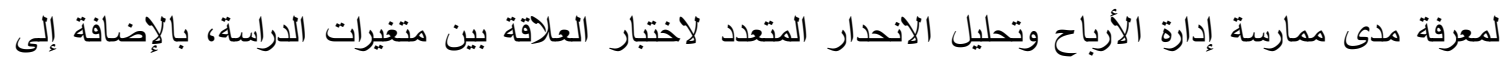

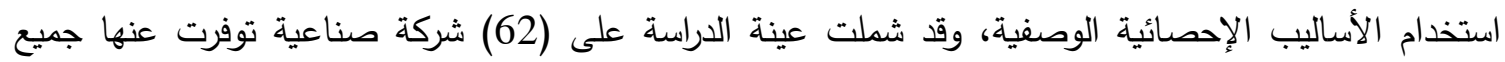
البيانات المطلوبة. ولقد توصلت الدراسة إلى أن الثركات التي تم اختبارها في عينة الدراسة قد مارست إدارة الأرباح بشكل متفاوت خلال فترة الدراسة (2010) وقد أشارت نتائج الانحدار المتعدد إلى وجود علاقة عكسية ذات دلالة

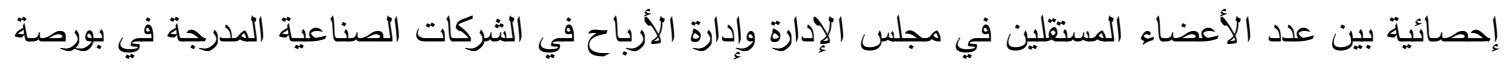
عمان، وكذلك وجود علاقة عكسية ذات دلالة إحصائية بين حجم المنشأة وإدارة الأرباح في الثركات الصناعية المدرجة في بورصة عمان. كما أوصت الدراسة بضرورة توعية كافة الأطراف المعنية بأهمية موضوع ممارسة إدارة الأرباح والآثار السلبية التي تحملها في طياتها هذه الممارسات في حال تم استغلالها للمصالح الثخصية، كما

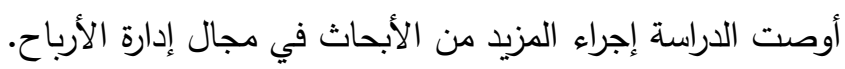

7. دراسة (Mitani: 2010) بعنوان: "أدلة إضافة عن إدارة الأرباح وحوكمة الثركات"

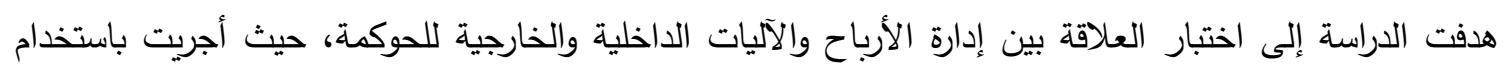
بيانات 799 شركة يابانية للفترة من 1999-2004، وقد استخدمت هذه الدراسة المنهج الوصفي التحليلي. وقد الدات توصلت الدراسة إلى وجود علاقة بين تركز الملكية وإدارة الأرباح وهي علاقة غير خطية، إذ تكون العلاقة بين المتغيرين طردية إلى حد نسبة معينة لا تتجاوز بنسبة الملكية 8\% ثم تبل تبدأ هذه العلاقة بالتغير نحو الارتباط السلبي

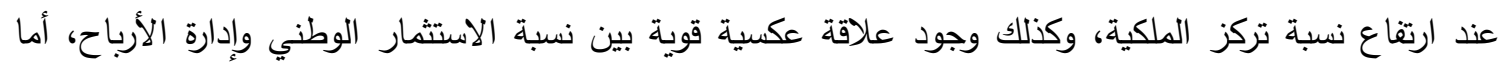

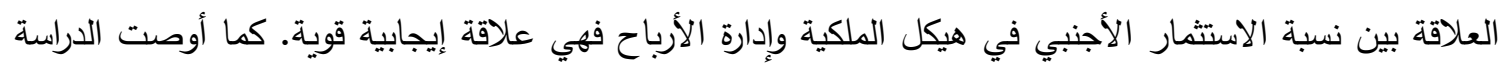

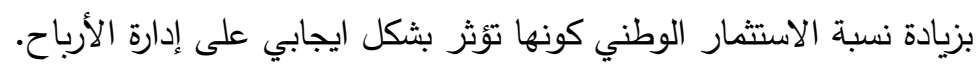

8. دراسة (أبو عجيلة وحمدان: 2009) بعنوان: "أثر الحوكمة المؤسسية على إدارة الأرباح (دليل من "الأردن) هدفت الدراسة إلى اكتشاف مدى ممارسة الثركات الصناعية الأردنية المدرجة ببورصة عمان لإدارة الأرباح، وأيضا قياس مدى تطبيق تلك الثركات لقواعد الحوكمة المؤسية،، ومن ثم تكوين علاقة بين المتغيرين (إدارة الأرباح والحوكمة المؤسية). حيث تم قياس إدارة الأرباح من خلال نموذج جونز المعدل (1995)، وتم قياس الحوكمة من خلال قواعد الحوكمة المؤسسية المتمثلة في (استقلالية لجنة التدقيق، استقلالية مجلس الإدارة). وقد الداجد توصلت الدراسة إلى نتائج أهمها أن الثركات الصناعية المدرجة ببورصة عمان مارست إدارة الأرباح خلال سنوات الدراسة من 2001-2006، وتوصلت أيضا لوجود علاقة عكسية بين عناصر الحوكمة المؤسية

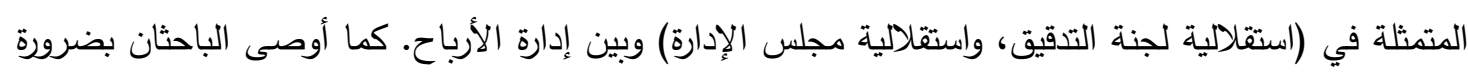

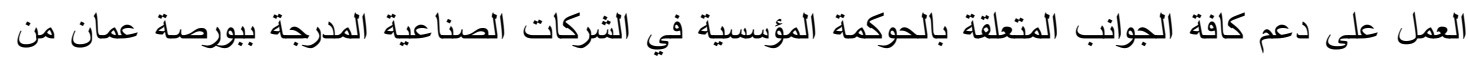
خلال تفعيل عناصر الحوكمة المؤسية من خلال منح الاستقلالية للجنة التدقيق ومجلس الإدارة التي من شأنها

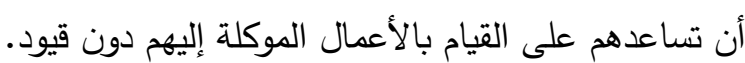


9 9. دراسة (Shah, Butt \& Hasan, 2009) بعنوان: "حوكمة الشركات وإدارة الأرباح ـأدلة ميدانية من

الثركات الباكستانية"

هدفت الدراسة الى اختبار العلاقة بين جودة حوكمة الثركات وإدارة الأرباح وذلك على عينة مكونة من (53) شركة

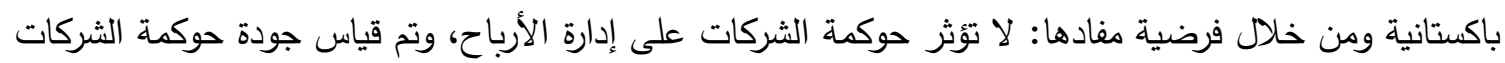
من خلال ثلاثة أبعاد مجتمعة هي هيكل مجلس الإدارة وهيكل الملكية واستقلالية لجنة التدقيق، أما هيكل مجلس التس

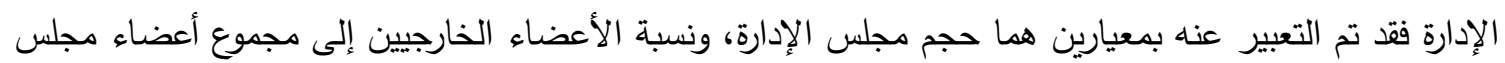
الإدارة، أما بعد هيكل الملكية فقد عبر عنه الباحثان في هذه الدراسة بمقياسين هما نسبة مجموع ما يملكه أكبر الإدير

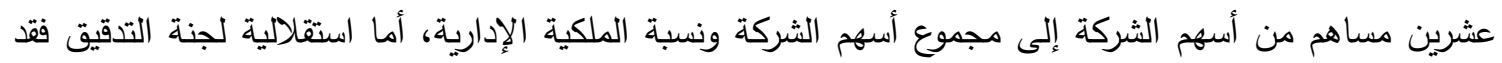
مثلت في نموذج الاختبار بنسبة عدد أعضاء المستقلين في لجنة التدقيق إلى إجمالي عدد أعضاء لجنة التدقيق.

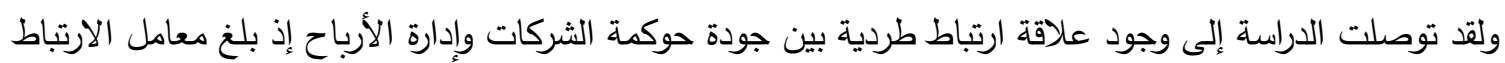
(31\%) وترجع هذه النتيجة الموجبة بين المتغيرين إلى ممارسات إدارة الأرباح ذات الطبيعة الموجبة في الشركات

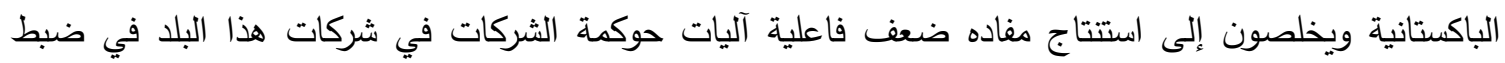

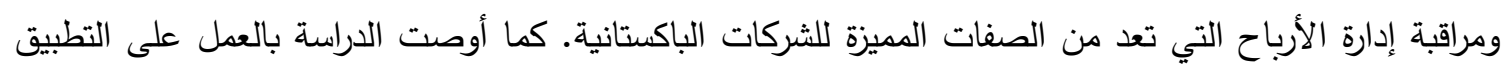

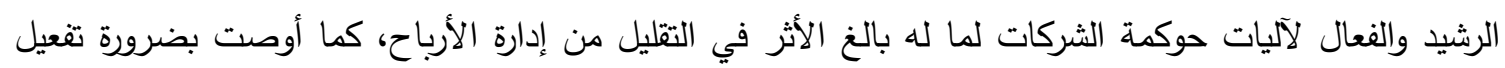
دور سوق المالي في الحد من إدارة الأرباح.

10 10دراسة (Shen \& Hsiang, 2007) بعنوان: "إدارة الأرباح وحوكمة الثركات في الأسواق المالية بآسيا"

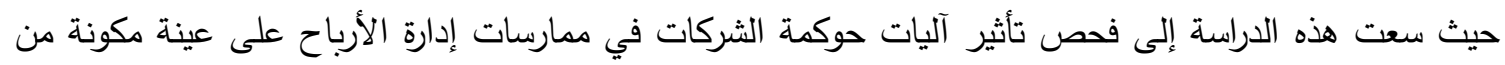
(495) شركة موزعة على تسعة دول وهي (هونغ كونغ، والهند، واندونيسيا، وكوريا، وماليزيا، والفلبين، وتايوان،

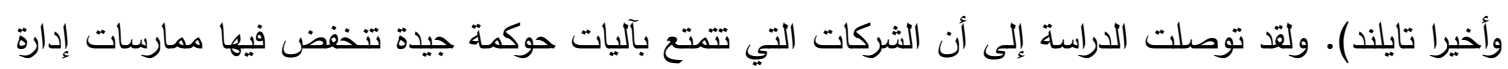
الأرباح، وأن الشركات الكبيرة الحجم تكون أكثر عرضة لظاهرة إدارة الأرباح رغم وجود آليات كفؤ، كما بينت النتائج

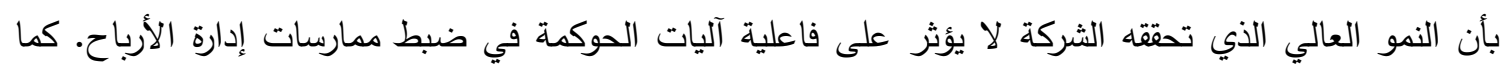

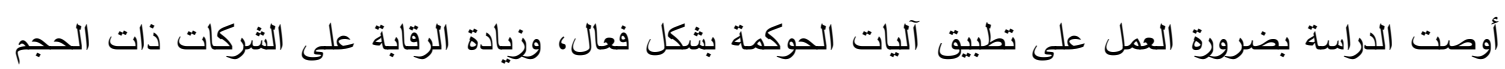
الكبير من قبل سوق رأس المال.

11 .دراسة (Osma \& Noguer, 2005) بعنوان: "حوكمة الثركات وإدارة الأرباح في اسبانيا" هدفت هذه الدراسة اختبار مدى تأثير ارتفاع مستوى آليات الحوكمة في الحد من ظاهرة إدارة الأرباح في الثركات

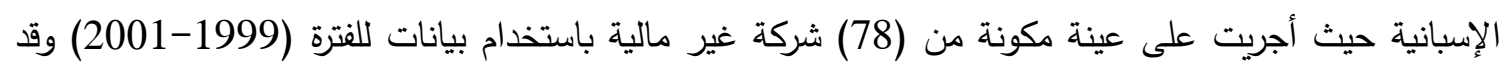

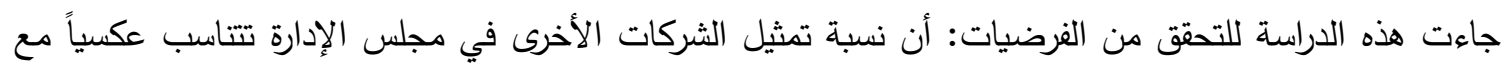

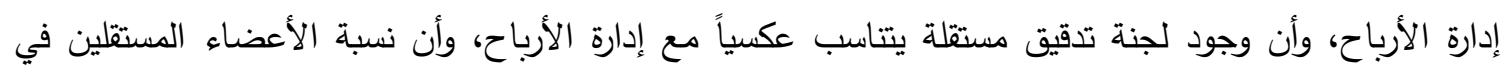

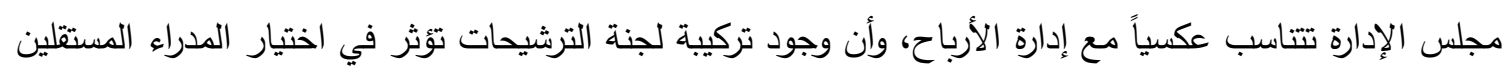

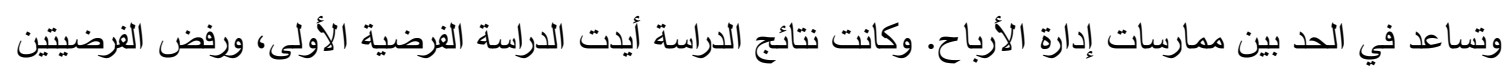
الثانية والثالثة، وأظهرت النتائج أن نسبة الأعضاء الخارجين في مجلس الإدارة لا يؤثر على ممارسات إدارة الأرباح

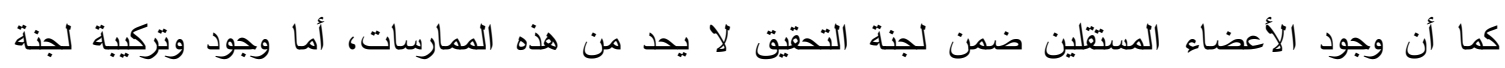

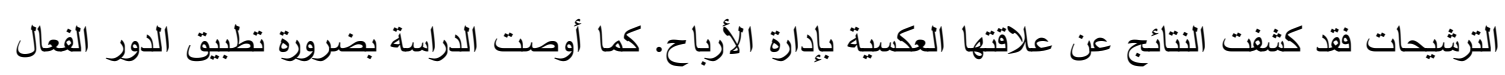


من قبل الأعضاء المستقلين في كل من مجلس الإدارة، و لجنة التحقيق لما له الأثر في الحد من ممارسات إدارة الأرباح.

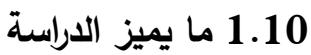

تعد هذه الدراسات من الدراسات القيلة التي تتاولت أثز حوكمة الشركات على إدارة الأرباح في فلسطين من ناحية التطبيق لهذه الدراسة ومتغيرات وطرق قياس هذه الدراسة، حيث تم الاعتماد في هذه الدراسة على المعلومات والأرقام المنشورة في التقارير المالية السنوية لثركات الدراسة، مما يعطي مصداقية الكاتية أكثر من الاستبيانات. أيضاً

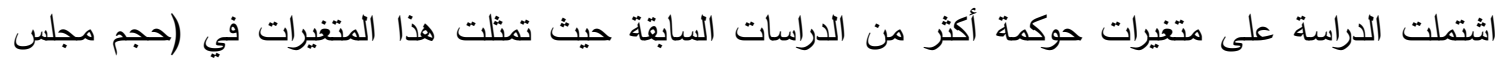

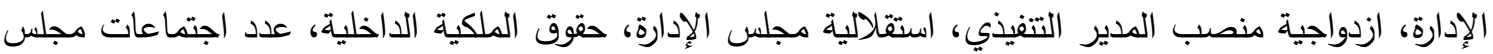

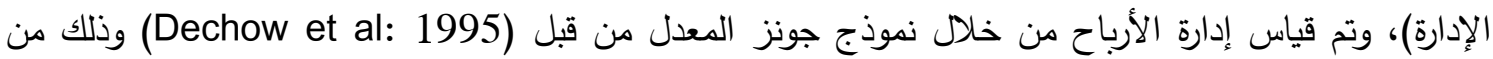

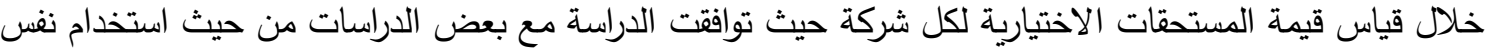
النموذج، بالإضافة لذلك أنه سوف يتم تطبيق هذه الدراسة على الثركات (الصناعية و الخدمية) الددرجة في بورصة فلسطين للعام (2018) حيث تعتبر سنة الدراسة حديثة وجاءت بعد تطور كبير في قواعد الحوكمة

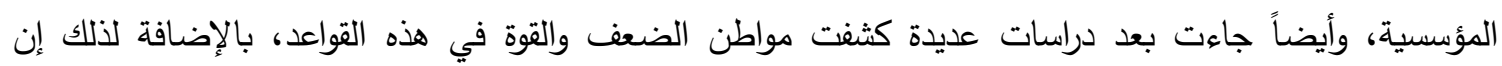

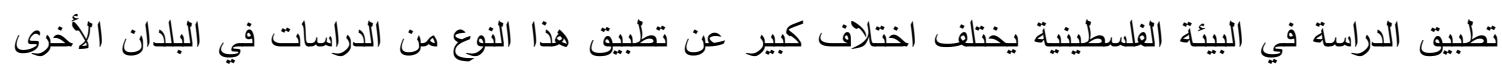
ويرجع ذلك إلى طبيعة المناخ الاقتصادي والسياسي السائد في كل دولة.

\section{وقد تم الاستفادة من الدراسات السابقة من حيث:}

- ساعدت الدراسات السابقة الباحث في بناء الإطار النظري. - ساعدت الدراسات السابقة الباحث في بناء أداة الدراسة وطريقة تطبيقها. - استفاد الباحث من الدراسات السابقة في تحليل النتائج وتقديم التوصيات.

منهجية الاراسة

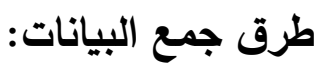

تم جمع البيانات من خلال المصادر التقارير المالية للثركات موضوع الدراسة للحصول على البيانات اللازمة البات الترات

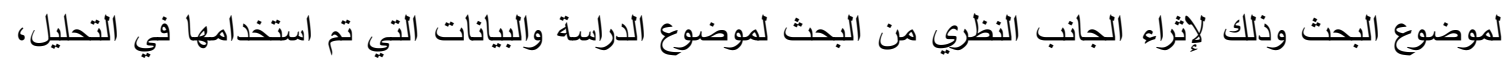

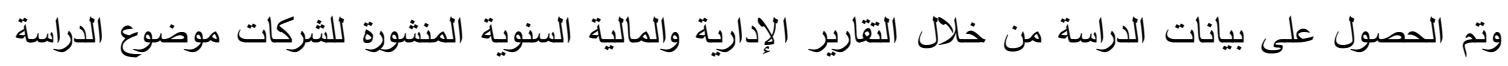

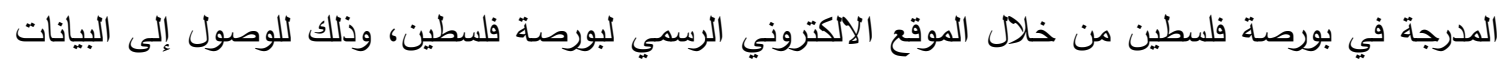
اللازمة لقياس أثر الحوكمة على إدارة الأرباح. مجتمع وعينة الاراسة:

1. مجتمع الاراسة: جميع الثركات المدرجة أسهمها في سوق فلسطين للأوراق المالية والبالغ عددها (48) شركة، والموزعة على خمس قطاعات مختلفة، وهي (البنوك، التأمين، الاستثمار، الخدمات،

$$
\text { والصناعة) }
$$

2. عينة الدارسة: الشركات الصناعية والخدمية الددرجة أسهها في سوق فلسطين للأوراق المالية والتي تمتلك بيانات مالية منشورة في الفترة من 2010-2017، وتم استبعاد القطاعات المالية مثل (البنوك،

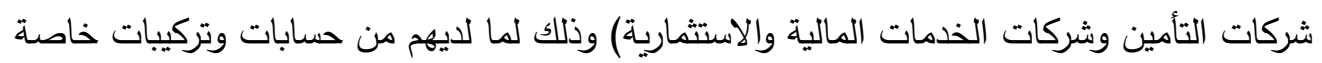


(Carcello and Nagy,2004)، وملكيات معقدة تختلف عن حسابات الشركات الصناعية والخدمية، وأيضا هذه القطاعات غالبا ما يكون لها مستحقات مختلفة تختلف عن الشركات موضوع الدراسة (Turegun, 2016)، والموضحة بالجدول رقم 1 التالي:

جدول (1) عينة الاراسة

\begin{tabular}{|c|c|c|c|}
\hline القطاع & رمز الثركة & اسم الشركة & 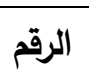 \\
\hline 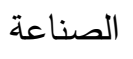 & APC & الثركة العربية لصناعة الدهانات & 1 \\
\hline الصناعة & AZIZA & دواجن فلسطين & 2 \\
\hline الصناعة & BPC & بيرزيت للأدوية & 3 \\
\hline 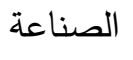 & GMC & مطاحن القهح الذهبي & 4 \\
\hline الصناعة & JCC & سجاير القدس & 5 \\
\hline الصناعة & JPH & القدس للمستحضرات الطبية & 6 \\
\hline الصناعة & $\mathrm{NCl}$ & الوطنية لصناعة الكرتون & 7 \\
\hline 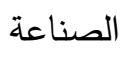 & VOIC & مصانع الزيوت النباتية & 8 \\
\hline 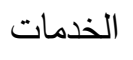 & $\mathrm{AHC}$ & المؤسسة العربية للفنادق & 9 \\
\hline 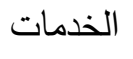 & NSC & مركز نابلس الجراحي التخصصي & 10 \\
\hline 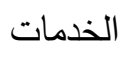 & PALTEL & الاتصالات الفلسطينية & 11 \\
\hline 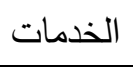 & PEC & الشركة الفلسطينية للكهرباء & 12 \\
\hline 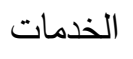 & WASSEL & الفلسطينية للتوزيع والخدمات اللوجستية & 13 \\
\hline
\end{tabular}

المصدر : اعداد الباحث بالاعتماد على بورصة فلسطين للأوراق المالية

النماذج المستخدمة: تم استخدام المنهج الكمي عن طريق استخدام بيانات السلاسل الزمنية المقطعية (Panel Data)، والتي تمثل بيانات عن مجموعة شركات العينة خلال الفترة الزمنية من 2010 حتى 2017، وذلك باستخدام البرنامج

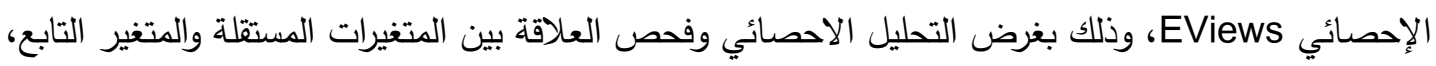
حيث تم قياس (المتغيرات المستقلة) حوكمة الشركات من خلال المتغيرات المذكورة بالجدول التالي:

جدول (2): طرق قياس المتغيرات المستقلة

\begin{tabular}{|c|c|c|}
\hline طريقة القياس & عناصر الحوكمة & 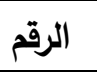 \\
\hline من خلال عدد أعضاء مجلس الإدارة المنشورة في التقارير & حجم مجلس الإدارة & .1 \\
\hline منصب عضأخذ مغير وهمي رقم (1) إذا كان يوجد ازدواجية في الإدارة والمدير التتفيذي، ويأخذ متغير & ازدواجية منصب المدير التتفيذي & .2 \\
\hline
\end{tabular}




\begin{tabular}{|c|c|c|}
\hline من خلال عدد الاجتماعات الموثق في التقارير الإدارية & عدد اجتماعات مجلس الإدارة & .3 \\
\hline مجموع مدا يملكه المدراء التنفيذيين من الأسهم مقسوماً على & حقوق الملكية الداخلية (\%) & .4 \\
\hline من خلاً على عدد المدراء غير التتفيذيين في مجلس الإدارة & استقلالية مجلس الإدارة (\%) & .5 \\
\hline
\end{tabular}

وسيتم قياس إدارة الأرباح وفق نموذج جونز المعدل من طرف Dechow \& al في عام 1995، من خلال الخطوات التالية:

1. الخطوة الأولى: حساب المستحقات الكلية وذلك بالاعتماد على منهج التدفقات النقدية في كل سنة من سنوات الدراسة من (2011-2017)، من

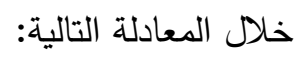

$$
\operatorname{TAC}(I, t)=N I(I, t)-\operatorname{CFO}(l, t)
$$

t المستحقات الكلية للشركة i اللسنة:TAC (l, t)

. صافي الدخل للشركة i NI (l, t)

.t للسنة i التدفق النقدي التشغيلي للشركة CFO (l, t)

$$
\text { 2. الخطوة الثانية: حساب المستحقات غير الاختيارية }
$$

حتى يتم حساب المستحقات غير الاختيارية نقوم بتقدير معالم نموذج جونز المعدل من خلال معادلة الانحدار لشركات العينة في جميع سنوات الدراسة من (2011-2017).

TAC $_{i, t} / \mathbf{A i}, \mathbf{t}-\mathbf{1}=\alpha \mathbf{0}+\alpha \mathbf{1}(\mathbf{l} / \mathbf{A i}, \mathbf{t}-\mathbf{1})+\alpha \mathbf{2}\left[\left(\Delta \mathbf{R E V i}_{i}, \mathbf{t}-\Delta\right.\right.$ REC $\left.\left._{i}, \mathbf{t}\right) / \mathbf{A i t}-\mathbf{1}\right]+\alpha \mathbf{3}$ ( PPEi,t $/ \mathbf{A i}, \mathbf{t}-\mathbf{1})+e i, t$.

. t المستحقات الكلية إلى إجمالي أصول الشركة i اللسنة: TAC

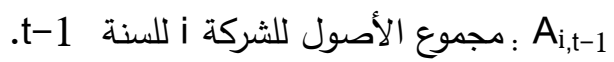
SREV $V_{i, t}$ A $\Delta_{R E C i, t}$

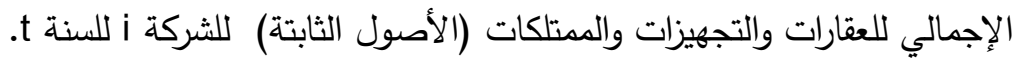
e 
فحصلنا على 91 معادلة انحدار متعدد لسنوات الدراسة من (2011-2017)، وبعد ذلك وباستخدام معالم نموذج الانحدار المقدرة (a1,a2,a3)، نقوم بتقدير قيمة المستحقات غير الاختيارية لشركات العينة، من خلال المعادلة

$\operatorname{NDAC}_{i, t} / \mathbf{A i}_{, \mathrm{t}-1}=\mathbf{a} 0+\hat{a}_{1}\left(\mathrm{I} / \mathrm{Ai}_{\mathrm{i}, \mathrm{t}-1}\right)+\hat{a}_{2}\left[\left(\Delta \operatorname{REV}_{\mathrm{i}, \mathrm{t}}-\Delta R E \mathrm{Ci}_{\mathrm{i}, \mathrm{t}}\right) / \mathrm{Ai}_{\mathrm{i}, \mathrm{t}-1}\right]+\hat{a}_{3}\left(\mathrm{PPE}_{\mathrm{i}, \mathrm{t}} /\right.$

$A_{i, t-1}$

$$
\text { بحيث }
$$

\section{3. الخطوة الثالثة: حساب المستحقات الاختيارية}

وهي عبارة عن الفرق بين المستحقات الكلية والمستحقات غير الاختيارية خلال فترة الدراسة من خلال

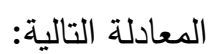

$\mathrm{DAC}_{\mathrm{i}, \mathrm{t}} / \mathbf{A}_{\mathrm{i}, \mathrm{t}-\mathbf{1}}=\mathrm{TAC}_{\mathrm{i}, \mathrm{t}} / \mathbf{A}_{\mathrm{it}-\mathbf{1}}-\mathrm{NDAC}_{\mathrm{i}, \mathrm{t}} / \mathbf{A}_{\mathrm{i}, \mathrm{t}-\mathrm{t}}$

t. المستحقات الاختيارية إلى إجمالي الأصول للشركة i في السنة:DAC $i, t / A_{i, t-1}$

اختبار الفرضيات وتحليل البيانات:

الإحصاء الوصفي لمتغيرات الدراسة:

\begin{tabular}{|c|c|c|c|c|c|c|}
\hline استقلالية & الدقاخلية & الاجتماعات & التدواجية & مجلس & إدارة الأرباح & متغيرات الدراسة \\
\hline 0.877 & 0.034 & 6.031 & 0.612 & 9.398 & 0.0785 & الوسط الحسابي \\
\hline 0.116 & 0.070 & 1.966 & 0.490 & 2.531 & 0.0752 & الانحراف المعياري \\
\hline 0.894 & 0.00014 & 6.000 & 1.000 & 9.000 & 0.0581 & الوسيط \\
\hline 0.545 & 0.000 & 1.000 & 0.000 & 5.000 & 0.0012 & أقل قيمة \\
\hline 1.000 & 0.261 & 12.000 & 1.000 & 15.000 & 0.447 & أكبر قيمة \\
\hline
\end{tabular}

جدول (3) : الإحصاء الوصفي لمتغيرات الدراسة

المصدر: اعداد الباحث بالاستتاد الى نتائج التحليل الاحصائي

يتضح من الجدول السابق ما يلي:

1. بالنسبة لإدارة الأرباح: يتضح من خلال الجدول (3) أن الثركات المعنية قامت بممارسة إدارة الأرباح

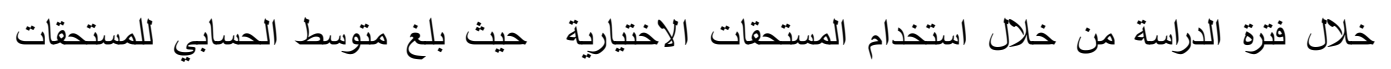

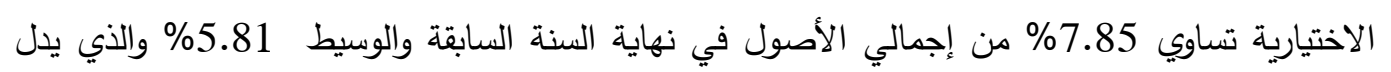

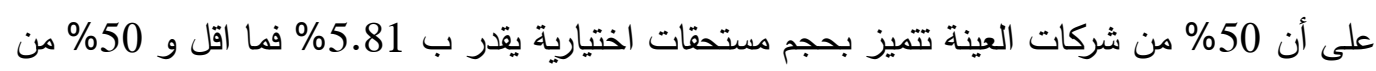

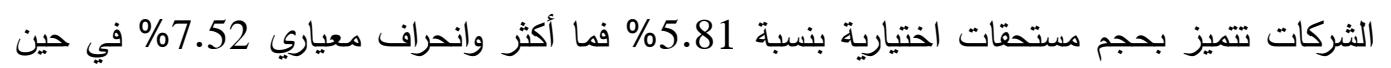


بلغت أعلى قيمة للمستحقات الاختيارية 44.7\%، أما ادني قيمة للمستحقات الاختيارية فقد بلغت $\% 0.12$

2. بالنسبة لحجم مجلس الإدارة: يتضح من خلال الجدول (3) أن المتوسط الحسابي لحجم مجلس الإدارة

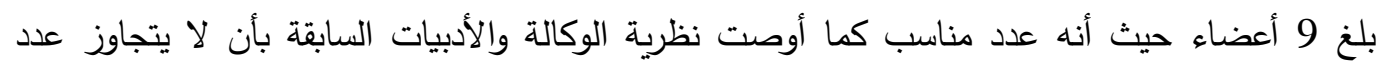

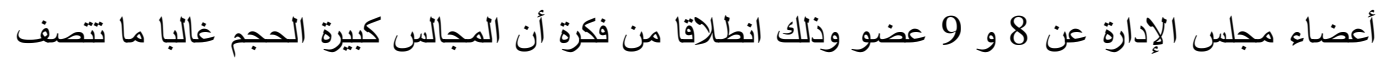
بصعوبة الاتصال وانخفاض فعالية القرارات المنفذة من قبله (Jensen, 1993)، وأما الوسيط فكان أيضاً 9 أعضاء والذي يدل على أن 50\% من الثركات العينة يتضمن مجالس إدارتها 9 أعضاء فما اقل و50\% المتبقية تتضمن مجالس إداراتها 9 أعضاء فما فوق وقيمة الانحراف معياري 2.531 في حين

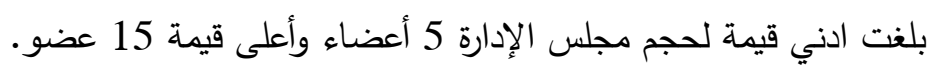
3. بالنسبة لازدواجية منصب المدير التنفيذي: يتضح من خلال الجدول (3) أن متوسط ازدواجية المدير التنفيذي قد بلغت 61.2\% والوسيط 100\% والذي يشير إلى أن 50\% من من شركات العينة كانت نسبة ازدواجية منصب المدير التتفيذي بها 100\% فما اقل و50\% المتبقية كانت نسبة ازدواجية منصب المدير التنفيذي بها 100\% فما أكثر وقد بلغ الانحراف المعياري 49.0\% في حين بلغت ادني قيمة لازدواجية

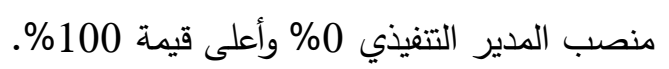
4. بالنسبة لعدد الاجتماعات: يتضح من الجدول (3) أن متوسط عدد اجتماعات مجلس الإدارة السنوية بلغ 6 اجتماعات والوسيط أيضاً 6 اجتماعات وهو يثير إلي أن 50\% من من شركات العينة اجتمعت مجلس الإنس إداراتها 6 اجتماعات فما اقل وال 50\% المتبقية اجتمع مجلس إدارتها 6 اجتماعات فما أكثر ، والانحراف المعياري بقيمة 1.966، وبلغ ادني قيمة لعدد اجتماعات مجلس الإدارة 1 وأعلى قيمة 12.

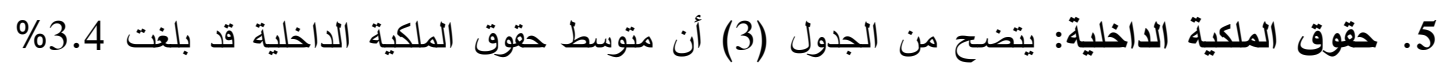
والوسيط 014.014 والذي يشير إلى أن 50\% من شركات العينة كانت نسبة حقوق الملكية الداخلية بها 0.014\% فما اقل وال 50\% المتبقية كانت نسبة حقوق الملكية الداخلية بها

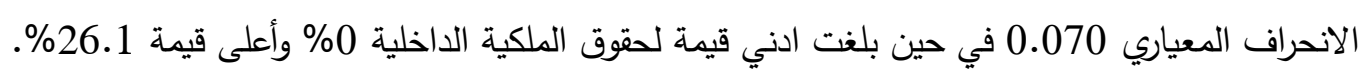
6. بالنسبة لاستقلالية مجلس الإدارة: يتضح من الجدول (3) أن متوسط استقلالية مجلس الإدارة في عينة

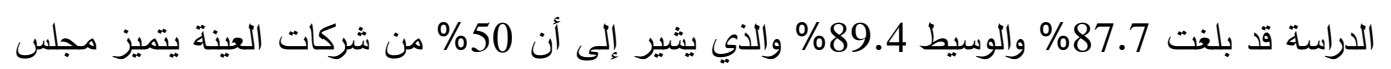

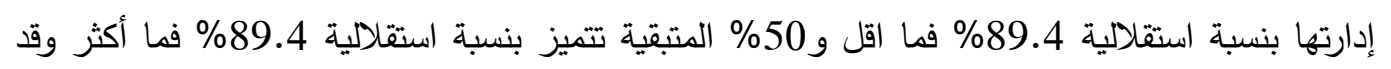
بلغ الانحراف المعياري 0.166 في حين بلغت ادني قيمة لاستقلالية مجلس الإدارة 54.5\% وأعلى بلى قيمة $\% 100$

جدول (4): جدول التكرار لمتغيرات الدراسة التي تأخذ قيمة صفر أو واحد

\begin{tabular}{|c|c|c|c|c|}
\hline التكرار النسبي المتجمع & التكرار النسبي & F التكرار F & الفئات & المتغير \\
\hline 37.4 & 37.4 & 34 & $\mathbf{0}$ & \multirow{3}{*}{ المدير التنفيذية منصب } \\
\hline \multirow[t]{2}{*}{100} & 62.6 & 57 & 1 & \\
\hline & 100.0 & 91 & المجموع & \\
\hline
\end{tabular}

المصدر: اعداد الباحث بالاستتاد الى نتائج التحليل الاحصائي 
يوضح الجدول (4) التكرار للمتغير الذي ليس لايه نسب لأعلى وأدنى نسبة، وذلك لأنها متغيرات وهمية، حيث تأخذ تلك المتغيرات إما قيمة صفر أو قيمة واحد صحيح. ومن الملاحظ من الجدول السابق، أن عدد التكرارات لازدواجية منصب المدير التنفيذي كان 57 تكراراً من مجموع 91 مشاهدة.

\section{مصفوفة الارتباط لمتغيرات الدراسة:}

جدول (5): مصفوفة الارتباط بيرسون بين متغيرات الدراسة قبل فحص التوزيع الطبيعي للبيانات

\begin{tabular}{|c|c|c|c|c|c|c|}
\hline الاستقلالية & الداخلكية & $\begin{array}{c}\text { الاجتماعات } \\
\text { الدد }\end{array}$ & الازدواجية & حجم مجلس الإدارة & إدارة الأرباح & متغيرات الدراسة \\
\hline & & & & & 1 & إدارة الأرباح \\
\hline & & & & 1 & *0.198- & حجم مجلس الإدارة \\
\hline & & & 1 & $* * 0.300$ & $/ / 0.125^{-}$ & الازدواجية \\
\hline & & 1 & $/ / 0.088$ & //0.102- & $/ / 0.062$ & عدد الاجتماعات \\
\hline & 1 & $* 0.244$ & $* * 0.359$ & //0.113- & //0.132- & حقوق الملكية \\
\hline 1 & $\begin{array}{c}- \\
* 0.617\end{array}$ & $/ / 0.053-$ & $\begin{array}{c}- \\
* * 0.490\end{array}$ & $/ / 0.166$ & $* 0.216$ & الاستقلالية \\
\hline
\end{tabular}

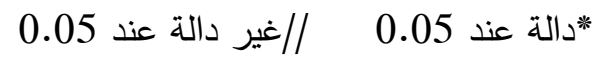

0.01 دالة 0.

المصدر : اعداد الباحث بالاستتاد الى نتائج التحليل الاحصائي دله دلدي

يتضح من الجدول السابق ما يلي:

1. يوجد علاقة ارتباط عكسية ذات دلالة إحصائية عند مستوى دلالة 0.05 بين حجم المستحقات الاختيارية وحجم مجلس الإدارة، أي أن حجم مجلس الإدارة له تأثير سلبي على سلوك إدارة الأرباح. 2. لا يوجد علاقة ارتباط ذات دلالة إحصائية عند مستوى دلالة 0.05 بين حجم المستحقات الاختيارية وازدواجية منصب المدير التنفيذي، أي أن ازدواجية منصب المدير ليس لها أي تأثير على سلوك إدارة الأرباح.

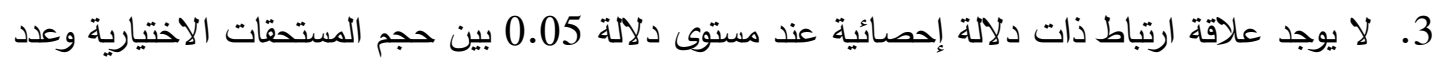

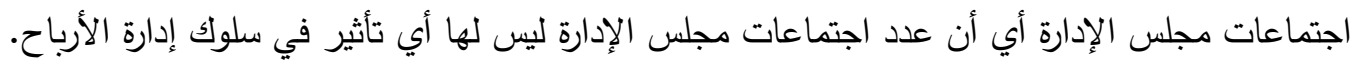
4. لا يوجد علاقة ارتباط ذات دلالة إحصائية عند مستوى دلالة 0.05 بين حجم المستحقات الاختيارية

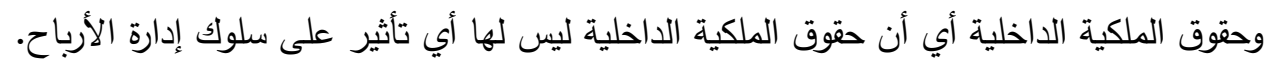

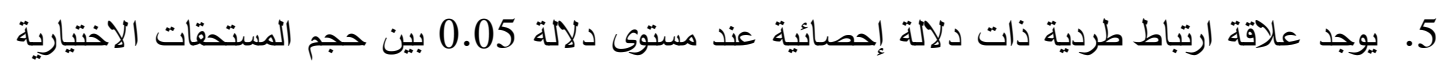

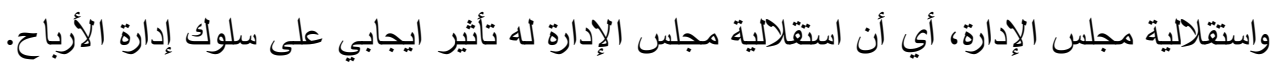


تحليل الانحدار المتعدد:

إن تطبيق الانحدار المتعدد يتم بتحقيق بعض الثروط كعدم وجود ازدواج أو تداخل خطي بين المتغيرات المستقلة، التوزيع الطبيعي لبيانات الدراسة والبواقي، وعدم وجود ارتباط ذاتي بين البواقي، وثبات تباين الخطأ العشوائي.

الازدواج الخطي بين المتغيرات المستقلة

من خلال الجدول السابق (5) يتضح أن جميع معاملات الارتباط بين المتغيرات المستقلة كانت اقل من 0.8

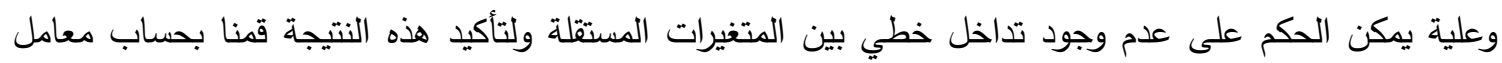
(معامل تضخم البيانات) كما يلي: (VIF)

\begin{tabular}{|c|c|c|}
\hline VIF & Tolerance & جدول (6): يوضح الال \\
\hline 1.309 & 0.764 & حجم مجلس الإدارة \\
\hline 1.676 & 0.597 & الازدواجية \\
\hline 1.103 & 0.907 & عدد الاجتماعات \\
\hline 1.748 & 0.572 & حقوق الملكية الداخلية \\
\hline 2.107 & 0.475 & الاستقلالية \\
\hline
\end{tabular}

المصدر : اعداد الباحث بالاستتاد الى نتائج التحليل الاحصائي

من خلال الجدول السابق (6) يتضح أن جميع قيم VIF كانت اقل من 5 وعليه يمكن الحكم على عدم وجود مشكلة التداخل الخطي بين المتغيرات المستقلة. اعتدالية التوزيع الطبيعي لبيانات الدراسة:

يعتبر هذا الثرط ضروري في حالة العينات صغيرة الحجم (اصغر من 30 مشاهدة) حيث أن عينة الدراسة تتضمن 91 مشاهدة يمكن افتراض اقتراب البيانات من توزيعها الطبيعي وفقاً لنظرية الحد المركزية، وعليه يمكن القول أن شرط التوزيع الطبيعي للبيانات محقق، ولكن لحساسية البيانات تم استخدام اختبار (Kolmogorov smirnov) لمعرفة هل البيانات تتبع التوزيع الطبيعي أو لا تتبع للتوزيع الطبيعي. لتئي

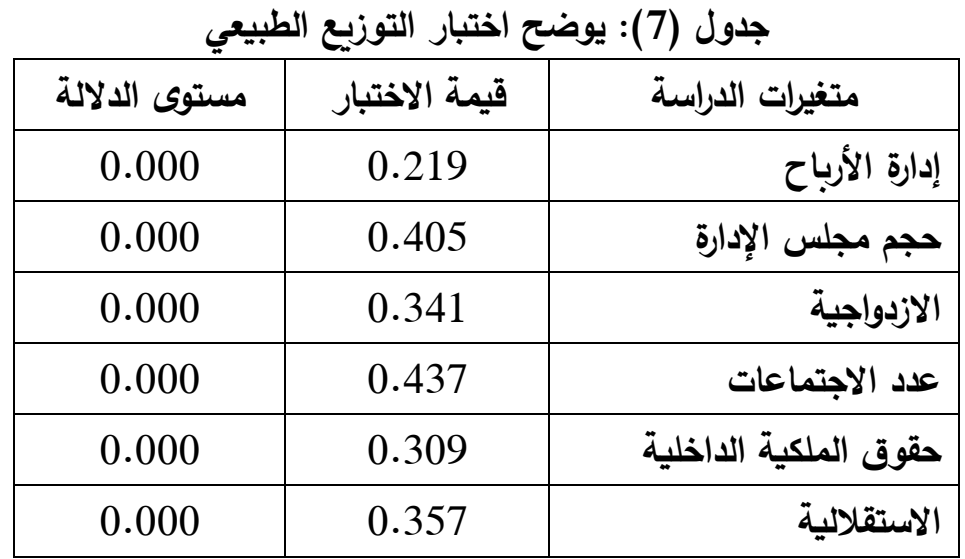

المصدر : اعداد الباحث بالاستتاد الى نتائج التحليل الاحصائي 
من خلال الجدول السابق (7) يتضح أن البيانات على طبيعتها لا تتبع التوزيع الطبيعي وتحتاج إلى تحويله رياضية لجعل البيانات تتبع التوزيع الطبيعي حيث تم استخدام التحولية التالية: المتغير المعدل = (x) حيث أن: X •Mean x وبعد عملية التحويل تم استخدام اختبار التوزيع الطبيعي (Kolmogorov smirnov) وجدنا أن البيانات تتبع التوزيع الطبيعي، وذلك يتضح من الجدول التالي:

\begin{tabular}{|c|c|c|}
\hline مستوى الدلالة & قيمة الاختبار & متغيرات الدراسة \\
\hline 0.198 & 0.119 & إدارة الأرباح المعدل \\
\hline 0.201 & 0.103 & حجم مجلس الإدارة المعدل \\
\hline 0.217 & 0.099 & الازدواجية المعدل \\
\hline 0.198 & 0.118 & عدد الاجتماعات المعدل \\
\hline 0.197 & 0.123 & حقوق الملكية الداخلية المعدل \\
\hline 0.180 & 0.187 & استقلالية مجلس الإدارة المعدل \\
\hline
\end{tabular}

من خلال الجدول السابق (8) يتضح أن البيانات أصبحت تتبع للتوزيع الطبيعي لان مستوى الدلالة أكبر من 5\%. الارتباط الذاتي بين البواقي: ويستخدم هذا الاختبار للتحقق من مدى وجود أو عدم وجود ارتباط ذاتي بين البواقي حيث تم استخدام اختبار (Durbin Watson) الموضح في الجدول التالي:

\begin{tabular}{|c|c|c|c|}
\multicolumn{4}{|c|}{ جدول (9): يوضح اختبار وجود ارتباط ذاتي بين البواقي } \\
\hline$-3.13 E-05$ & Mean dependent var & 0.535214 & R-squared \\
\hline 0.215783 & S.D. dependent var & 0.510232 & Adjusted R-squared \\
\hline 3.524123 & Akaike info criterion & 0.125354 & S.E. of regression \\
\hline 2.635241 & Schwarz criterion & 0.978987 & Sum squared resid \\
\hline 7.36325 & Hannan-Quinn criter. & 73.52397 & Log likelihood \\
\hline 2.035274 & Durbin-Watson stat & 11.3628 & F-statistic \\
\hline & & 0.000352 & Prob (F-statistic) \\
\hline
\end{tabular}

المصدر : اعداد الباحث بالاستتاد الى نتائج التحليل الاحصائي 
من خلا الجدول (9) يتضح أن قيمة داربن واتسون (DW) كانت محصورة بين القيمتين 1.5 و2.5 وعلية يمكن اتخاذ قرار بعدم وجود ارتباط ذاتي بين البواقي.

ثبات تباين الخطأ العشوائي: للتحقق من ثبات تباين الخطأ العشوائي تم استخدام اختبار (Gleiser) الموضح في الجدول التالي: جدول (10): يوضح اختبار ثبات تباين الخطأ العشوائي

\begin{tabular}{|c|c|c|c|}
\hline & \multicolumn{3}{|l|}{ Heteroskedasticity Test: Glejser } \\
\hline 0.5214 & Prob. F(5,92) & 1.002310 & F-statistic \\
\hline 0.4144 & Prob. Chi-Square(5) & 6.3215212 & Obs*R-squared \\
\hline 0.1192 & Prob. Chi-Square(5) & 8.635241 & Scaled explained SS \\
\hline
\end{tabular}
المصدر : اعداد الباحث بالاستتاد الى نتائج التحليل الاحصائي

من خلا الجدول (10) يتضح أن مستوى دلالة اختبار Gleiser كانت تساوي (0.4144) وهي أكبر من مستوى الدلالة 0.05 وهذا يعني انه لا يوجد مشكلة عدم ثبات تباين الخطأ العشوائي.

مصفوفة الارتباط لمتغيرات الدراسة:

جدول (11): يوضح مصفوفة الارتباط بيرسون بين متغيرات الدراسة بعد خضوعها للتوزيع الطبيعي

\begin{tabular}{|c|c|c|c|c|c|c|}
\hline الاستقلالية & الدالكية & $\begin{array}{c}\text { الاجتماعات } \\
\text { المددل }\end{array}$ & الازدواجية & حجم مجلس الإدارة & إدارة الأرباح & متغيرات الدراسة \\
\hline & & & & & 1 & إدارة الأرباح المعدل \\
\hline & & & & 1 & $* * 0.365-$ & حجم مجلس الإدارة \\
\hline & & & 1 & $* * 0.473$ & $* 0.417-$ & الازدواجية المعدل \\
\hline & & 1 & $/ / 0.108$ & $/ / 0.114-$ & $/ / 0.118$ & عدد الاجتماعات المعدل \\
\hline & 1 & $* 0.352$ & $* * 0.454$ & //0.197- & //0.110- & حقوق الملكية الداخلية \\
\hline 1 & $* * 0.597-$ & $\begin{array}{c}- \\
/ 0.048\end{array}$ & $\begin{array}{c}- \\
* * 0.539\end{array}$ & $/ / 0.107$ & $* 0.336$ & الاستقلالية المعدل \\
\hline
\end{tabular}

المصدر: اعداد الباحث بالاستتاد الى نتائج التحليل الاحصائي دند 


$$
\text { من خلال الجدول (11) يتضح انه: }
$$

1. يوجد علاقة ارتباط عكسية ذات دلالة إحصائية عند مستوى دلالة 0.05 بين حجم المستحقات الاختيارية

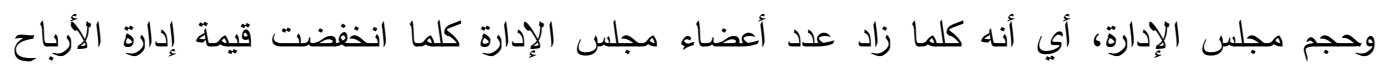

$$
\text { المتمثلة في قيمة المستحقات الاختيارية، والعكس صحيح. }
$$

2. يوجد علاقة ارتباط عكسية ذات دلالة إحصائية عند مستوى دلالة 0.05 بين حجم المستحقات الاختيارية وازدواجية منصب المدير التنفيذي أي أنه عندما يكون ازدواجية لدنصب المدير التتفيذي تتخفض قليهة

$$
\text { إدارة الأرباح المتمثلة في قيمة المستحقات الاختيارية، والعكس صحيح. }
$$

3. لا يوجد علاقة ارتباط ذات دلالة إحصائية عند مستوى دلالة 0.05 بين حجم المستحقات الاختيارية وعدد اجتماعات مجلس الإدارة أي أن عدد اجتماعات مجلس الإدارة ليس له أي تأثير في سلوك إدارة إلإة الأرباح. 4. ل لا يوجد علاقة ارتباط ذات دلالة إحصائية عند مستوى دلالة 0.05 بين حجم المستحقات الاختيارية الإداتية

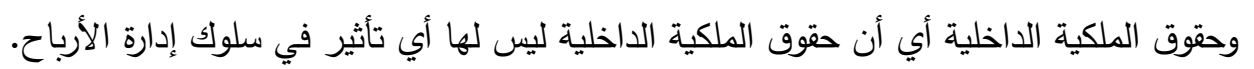
5. يوجد علاقة ارتباط طردية ذات دلالة إحصائية عند مستوى دلالة 0.05 بين حجم المستحقات الاختيارية

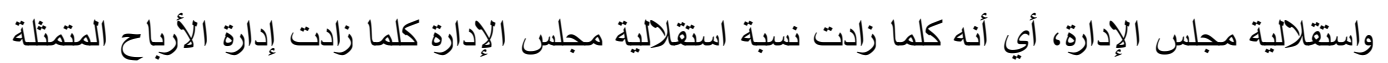

$$
\begin{aligned}
& \text { في قيمة المستحقات الاختيارية، والعكس صحيح. } \\
& \text { اختبار وتحليل الفرضيات: } \\
& \text { نتائج نموذج الانحدار المتعدد: }
\end{aligned}
$$

Panel بعد القيام بالاختبارات الإحصائية تبين أن أفضل طريقة لمعالجة البيانات هي طريقة البيانات الطويلة

\begin{tabular}{|c|c|c|c|c|}
\hline Prob. & $\mathrm{t}$-Statistic & Std. Error & Coefficient & Variable \\
\hline 0.0984 & 1.802 & 0.352421 & 0.635142 & C \\
\hline 0.0000 & -26.561 & 0.00123 & -0.03267 & حجم مجلس الإدارة المعدل \\
\hline 0.0012 & -2.237 & 0.03511 & -0.078541 & الازدواجية المعدل \\
\hline 0.4124 & 0.512 & 0.04185 & 0.021413 & عدد الاجتماعات المعدل \\
\hline 0.8397 & -0.353 & 0.374232 & -0.13214 & حقوق الملكية الداخلية المعدل \\
\hline 0.0000 & 2.996 & 0.032514 & 0.097413 & الاستقلالية المعدل \\
\hline$-3.12 \mathrm{E}-07$ & \multicolumn{2}{|c|}{ Mean dependent var } & 0.575231 & R-squared \\
\hline 0.125100 & \multicolumn{2}{|c|}{ S.D. dependent var } & 0.531544 & Adjusted R-squared \\
\hline-1.023511 & \multicolumn{2}{|c|}{ Akaike info criterion } & 0.103652 & S.E. of regression \\
\hline-1.112352 & \multicolumn{2}{|c|}{ Schwarz criterion } & 0.814638 & Sum squared resid \\
\hline
\end{tabular}

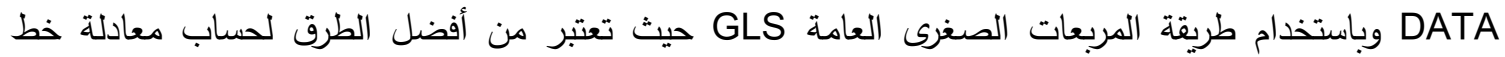
الانحدار المتعدد حيث يعد العالم (Aitken) مؤسس هذه الطريقة أنها أكثر شمولية في عملية حساب معادلة خط الانحدار المتعدد لتقليل حجم الأخطاء (راشد، صفوان. 2006)، ومن خلال تطبيق هذه الطريقة تحصلنا على ما مالى

جدول (12): يوضح نتائج نموذج الانحدار المتعدد الخاص بتأثير الحوكمة على إدارة الأرباح 


\begin{tabular}{|l|l|l|l|l|}
\hline-1.527887 & \multicolumn{2}{|c|}{ Hannan-Quinn criter. } & 100.30250 & Log likelihood \\
\hline 2.053 & \multicolumn{2}{|c|}{ Durbin-Watson stat } & 11.63852 & F-statistic \\
\hline & & & 0.0000012 & Prob (F-statistic) \\
\hline
\end{tabular}

$$
\text { من خلال الجدول (12) يتضح أن: }
$$

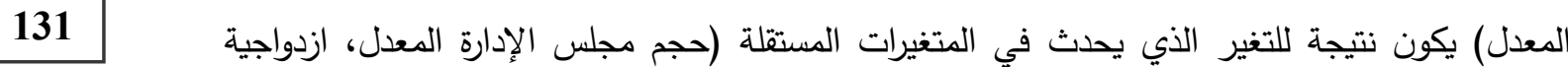
منصب المدير المعدل، عدد الاجتماعات المعدل، حقوق الملكية الداخلية المعدل، استقلالية مجلس الإدارة المعدل)، وهذا يعني أن حوكمة الشركات تقسر (57.5\%) من التغير الذي يحدث في حجم المستحقات الاختيارية على مستوى الشركات التابعة في بورصة فلسطين أما النسبة المتبقية هي (42.5\%) فهير لهي نتيجة لعوامل أخرى. 2. قيمة مستوى الدلالة اختبار F تساوي 0.000 وهي اقل من مستوى الدلالة 0.05 وهذا يعني إن النموذج معنوي 3. قيمة اختبار DW كانت قيمته 2.053 وهي محصورة بين القيمتين 1.5 و2.5 وعليه لا يوجد ارتباط ذاتي بين البواقي.

\section{فرضيات الدراسة والتعليق عليها:}

1. اختبار الفرضية الأولى التي تنص على " لا يوجد أثر ذا دلالة إحصائية عند مستوى دلالة (

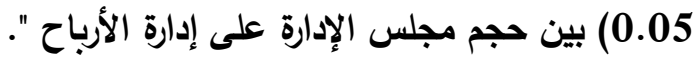

من خلال الجدول السابق رقم (12) يتضح انه يوجد أثر سلبي ذات دلالة إحصائية عند مستوى دلالة 0.05 بين حجم مجلس الإدارة وإدارة الأرباح على مستوى شركات قطاع الصناعة وقطاع الخدمات التابعة لبورصة فلسطين، وهذا يعني انه كلما زاد عدد أعضاء مجلس الإدارة كلما قلت أو انخفضت إدارة الأرباح، وعليه يتم

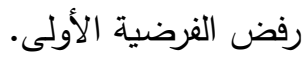

حيث اتفقت نتيجة الفرضية الأولى مع دراسة (Alareeni: 2018) المطبقة على بورصة البحرين، ودراسة (ريشي: 2017) المطبقة على الثركات الفرنسية المدرجة تحت مؤشر (CAC40) في الجزائر، كما اختلفت نتيجة الدراسة مع دراسة (Ramachandran, et. at: 2014) المطبقة في بورصة سنغافورة، ودراسة (الفضل وحمد: 2014) المطبقة في بورصة العراق، ودراسة (shah, butt \& Hasan: 2009)

$$
\text { على عينة من الشركات الباكستانية. }
$$

من الواضح وجود تضارب بين الاتفاق والتعارض في النتيجة مع نتيجة الدراسة الحالية، ويرجع السبب من وجهة نظر الباحث في اتفاق نتيجة الدراسة الحالية مع دراسة (Alareeni: 2018) و دراسة (ريشي: 2017)

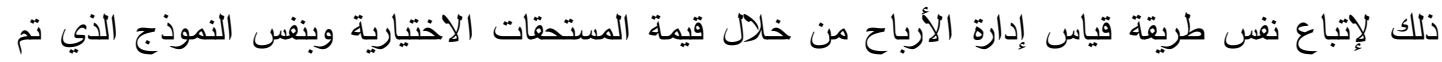

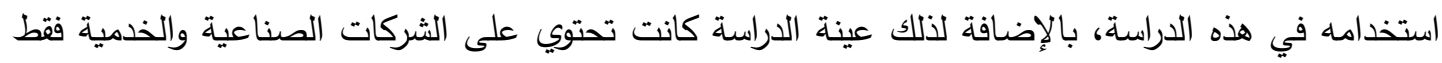
وتم استثناء الشركات ذات الطابع المالي لهيكلها المالي المختلف عن الهياكل المالية الأخرى، وبالنسبة للدراسات التي تعارضت نتيجتها مع نتيجة الدراسة الحالية من رأي الباحث يرجع ذلك لعدم تثابه التطبيق في الدراسة الحالية والدراسات المتعارضة معها حيث في دراسة (Ramachandran, et al:2004) تم استخدام 
نفس نموذج الدراسة الحالية في قياس إدارة الأرباح إلا انه تم أخذ جميع الثركات المدرجة في بورصة سنغافورة بما فيها الشركات ذات الطابع المالي، وفي دراسة (الفضل وحمد: 2014) تم قياس قواعد الحوكمة من خلال

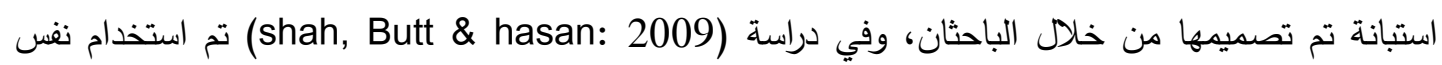
النموذج المطبق في الدراسة الحالية لقياس ادارة الأرباح، ويعزو الباحث الاختلاف في نتائج البحث ربما لبعان لبعد

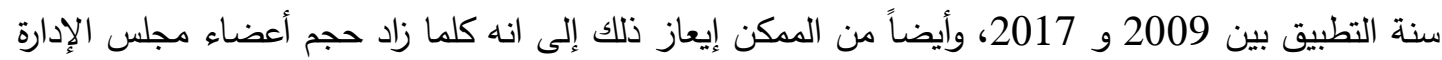

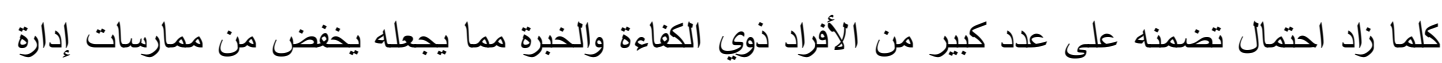
الأرباح، وفي النهاية الاختلاف يعود لطبيعة البلاد المطبقة فيها الدراسة وطبيعة العينة التي تم اختيارها،

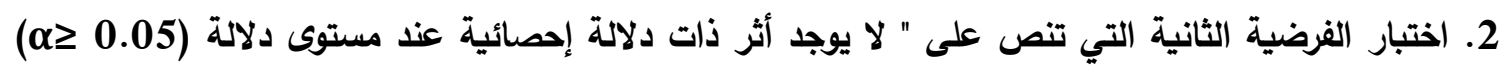
بين ازدواجية نصيب المدير التنفيذي على إدارة الأرباح" من خلال الجدول السابق رقم (12) يتضح انه يوجد أثر سلبي ذا دلالة إحصائية عند مستوى دلالة 0.05 بين ازدواجية منصب المدير التنفيذي وإدارة الأرباح على مستوى شركات قطاع الصناعة وقطاع الخدمات التابعة

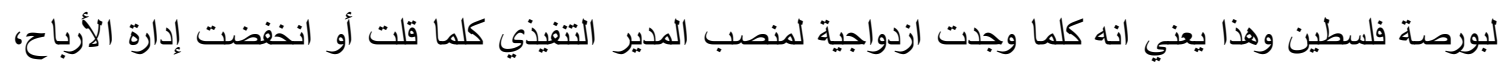
وعليه يتم رفض الفرضية الثانية.

حيث لم تتفق نتيجة الفرضية الثانية مع أي من الدراسات السابقة، حيث أثبتت نتيجة دراسة (Alareeni: 2018) المطبقة على بورصة البحرين أنه لا يوجد علاقة بين ازدواجية منصب المدير التتفيذي وإدارة الأرباح، وأثبتت نتيجة دراسة (ريشي: 2017) المطبقة على الثركات الفرنسية المدرجة تحت مؤشر (CAC40) في الجزائر وجود علاقة لونة طردية بين ازدواجية منصب المدير التتفيذي وإدارة الأرباح. ويبدو من ظاهر الأمر أن الازدواجية لم يكن لها تأثير سلبي على إدارة الأرباح، في حين أن المبادئ العلمية،

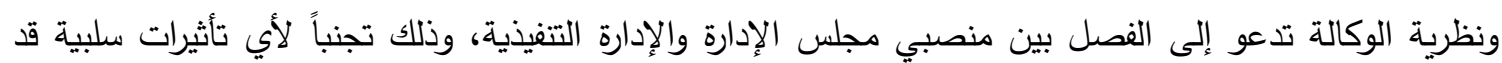

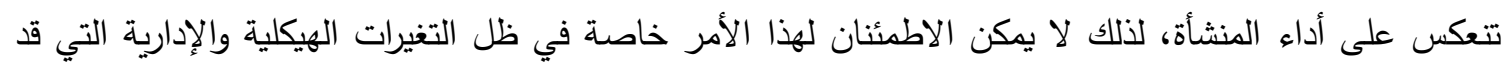
تحدث في البيئة الدحيطة بعمل تلك الثركات، ولكن ربما تكون الازدواجية بين منصب المدير التنفيذي وعضو

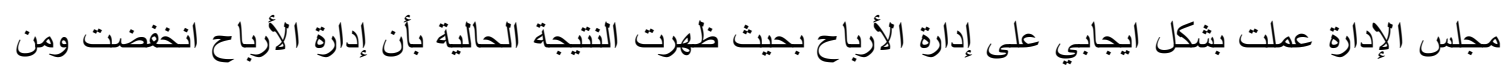

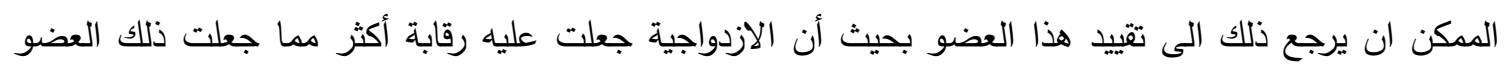

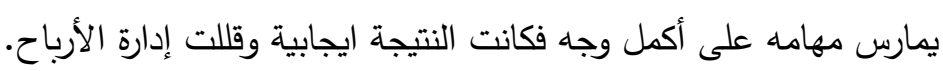

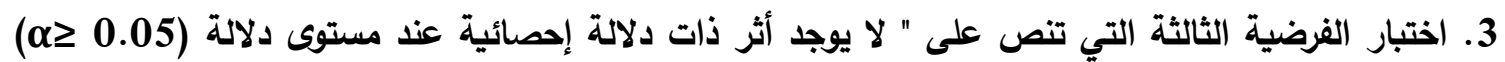

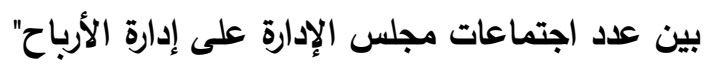
من خلال الجدول السابق رقم (12) يتضح انه لا يوجد أثر ذا دلالة إحصائية عند مستوى دلالة 0.05 بين عدد الإداء اجتماعات مجلس الإدارة وإدارة الأرباح على مستوى شركات قطاع الصناعة وقطاع الخدمات التابعة لبورصة فلسطين وعلية يتم قبول الغرضية الثالثة.

حيث اتفقت نتيجة الفرضية الثالثة مع نتيجة دراسة (Ramachandran, et. at: 2014) المطبقة في بورصة سنغافورة. 


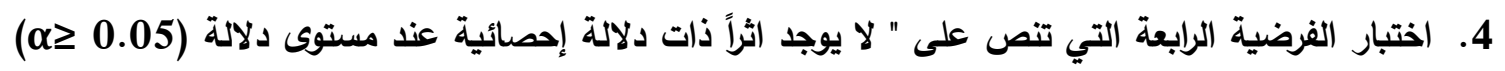
بين حقوق الملكية الداخلية على إدارة الأرباح"

من خلال الجدول السابق رقم (12) يتضح انه لا يوجد أثراً ذا دلالة إحصائية عند مستوى دلالة 0.05 بين حقوق الأل الملكية الداخلية وإدارة الأرباح على مستوى شركات قطاع الصناعة وقطاع الخدمات التابعة لبورصة فلسطين وعليه

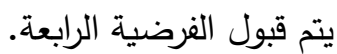

في حين اختلفت نتائج الدراسات السابقة مع نتيجة الفرضية الرابعة للدراسة الحالية، حيث أظهرت نتيجة دراسة (Mitani: 2010)

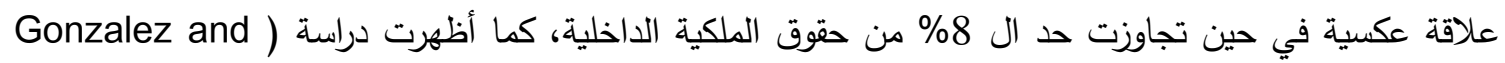

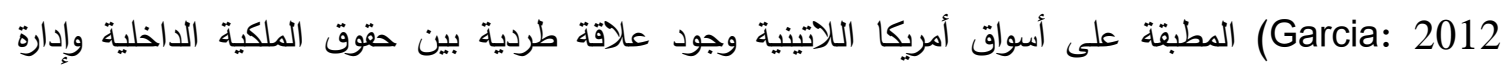

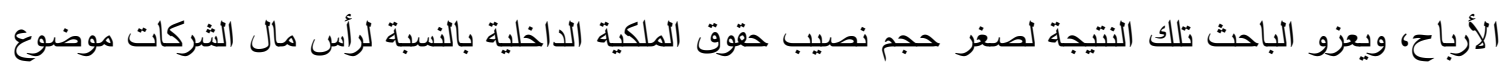

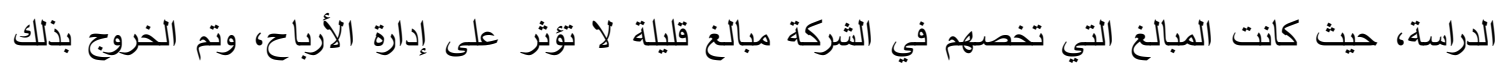
التفسير من خلال جمع البيانات الإدارية والمالية للشركات.

5. اختبار الفرضية الخامسة التي تنص على " لا يوجد أثر ذات دلالة إحصائية عند مستوى دلالة (

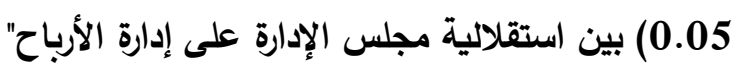
من خلال الجدول السابق رقم (12) يتضح انه يوجد أثر ايجابي ذات دلالة إحصائية عند مستوى دلالة 0.05 بين الإداح استقلالية مجلس الإدارة وإدارة الأرباح على مستوى شركات قطاع الصناعة وقطاع الخدمات التابعة لبورصة فلسطين، وهذا يعني انه كلما زادت استقلالية مجلس الإدارة تزداد إدارة الأرباح وعليه يتم رفض الإدات الفرضية الخامسة. حيث اتفقت نتيجة الفرضية الخامسة مع نتيجة دراسة (Alareeni: 2018) المطبقة على بورصة البحرين، ودراسة (shah, butt \& Hasan: 2009)

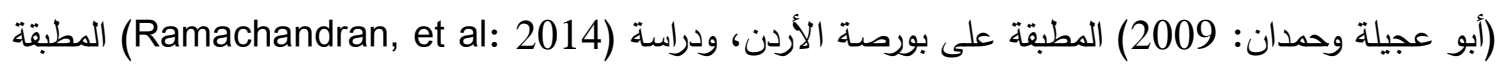
على بورصة سنغافورة، ودراسة (ريشي: 2017) المطبقة على الثركات الفرنسية المدرجة تحت مؤشر في الجزائر، ودراسة (الفضل وحمد: 2014) المطبقة على بورصة العراق، ودراسة (المصطفى: 2012) المطبقة على بورصة الأردن عن وجود علاقة عكسية بين استقلالية مجلس الإدارة وإدارة الأرباح، وأخيرا أثبتت دراسة ولتهة (Osma \& Noguer: 2005)

من الظاهر وجود اتفاق بين نتيجة الفرضية الخامسة وبعض الدراسات، وأيضا وجود اختلاف بالنتائج مع باقي الدراسات الأخرى، حيث أثتتت النتيجة وجود علاقة طردية بين المتغيرين، وربما يرجع ذلك لعدم تأثير الأعضاء

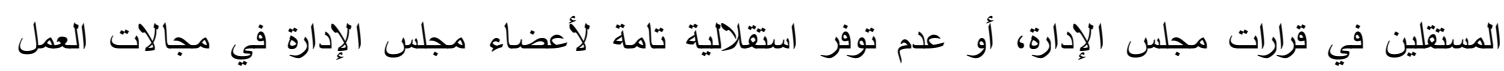
التتفيذي، أو أنهح مستقلين بشكل صوري بحيث يتماشون مع قرارات الإدارة العليا، ومن الممكن أن يكون بسبب الإداء

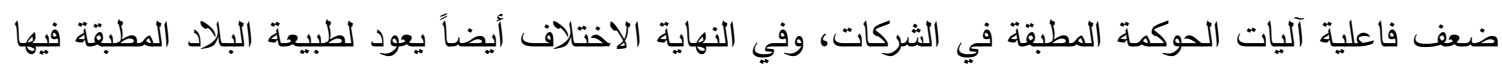
الدراسة وطبيعة وحجم العينة التي تم اختيارها، وسنوات البيانات، والبيئة الاقتصادية، والنماذج المستخدمة. نتائج الدراسة:

1. أظهرت الدراسة أن الشركات الصناعية والخدمية التي تم دراستها في هذه الدراسة قد قامت بممارسة إدارة الأرباح خلال فترة الدراسة ولكن بنسب متفاوتة. 
2. أظهرت نتيجة الدراسة أن 57.5\% من التغير الذي يحدث في إدارة الأرباح يكون نتيجة للتغير الذي

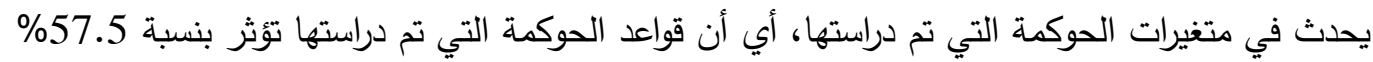
على إدارة الأرباح، والنسبة المتبقية ترجع لعوامل ومؤثرات أخرى.

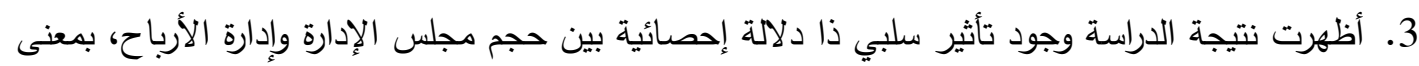
انه كلما زاد عدد أعضاء مجلس الإدارة، كلما انخفضت إدارة الأرباح، والعكس صحيح. 4. أظهرت الدراسة وجود تأثير سلبي ذا دلالة إحصائية بين ازدواجية منصب المدير الإدادير التتفيذي وبين إدارة

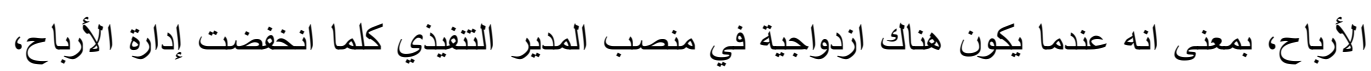

$$
\text { والعكس صحيح. }
$$

5. أظهرت الدراسة وجود تأثير ايجابي ذا دلالة إحصائية بين استقلالية مجلس الإدارة، وإدارة الأرباح، بمعنى أنه كلما زادت استقلالية مجلس الإدارة كلما ارتقعت إدارة الأرباح. 6. أظهرت الدراسة عدم وجود أي علاقة مؤثرة بين كلا من (عدد اجتماعات مجلس الإدارة وحقوق الملكية الاخلية) وإدارة الأرباح. توصيات الدراسة: 1. أوصت الدراسة بضرورة الاستمرار في تعزيز قواعد الحوكمة لتلافي التأثيرات السلبية التي تترتب على غياب تطبيقات هذه القواعد. 2. أوصت الدراسة مراعاة تدعيم استقلالية أعضاء مجلس الإدارة، ومنحهم الاستقلالية التامة في علاقتهم بمجالات العمل التتفيذي، تجنباً لاتخاذ قرارات قد تؤثر على عملية إدارة الأرباح. 3. ضرورة مراعاة الفصل بين وظائف مجلس الإدارة والإدارة التتفيذية، بحيث لا يتم الربط بين وظائف مجلس لاتس لاتس

$$
\text { الإدارة الإشرافية والأعمال التنفيذية. }
$$

4. ضرورة زيادة الوعي بأهمية حوكمة الشركات وعمل ورش العمل التي تهدف إلى تثقيف العاملين والإدارات العليا بضرورة تطبيق قواعد الحوكمة بالوجه الذي يمنع الانحرافات. 5. ضرورة استمرار التطبيق لقواعد الحوكمة، والانتقال بها من الجانب النظري إلى الجانب العملي والفعال

$$
\text { على أرض الواقع. }
$$

6. ضرورة الاستمرار في عمل الأبحاث الأخرى التي تتعلق بنفس الموضوع مع الأخذ بعين الاعتبار فحص

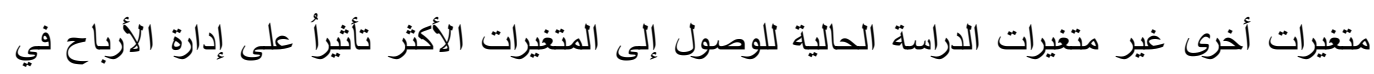
الشركات المدرجة في بورصة فلسطين.

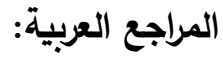

أبو عجيلة، عماد محمد وحمدان، علام محمد (2009):"أثر الحوكمة المؤسسية على إدارة الأرباح -ـليل من

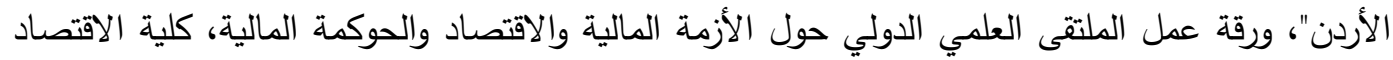

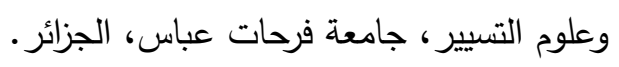

الأسرج، حسين عبد المطلب (2012): "حوكمة الصناديق الوقفية بين النظرية والتطبيق"، رسالة ماجستير غير

$$
\text { منشورة، معهد التخطيط القومي، مصر • }
$$

تلاحمة، خالد إبراهيم (2012): "حوكمة الثركات المساهمة في فلسطين -النظرية والتطبيق"، المجلة الأردنية في القانون والعلوم السياسية 4 (3). 
حمودي، أسماء (2015): "جودة المعلومات المحاسبية في تفعيل حوكمة الشركات -ـراسة حالة شركة بناء الهياكل المعدنية المصنعة أم البواقي"، رسالة ماجستير غير منشورة، جامعة أم البواقي، الجزائر .

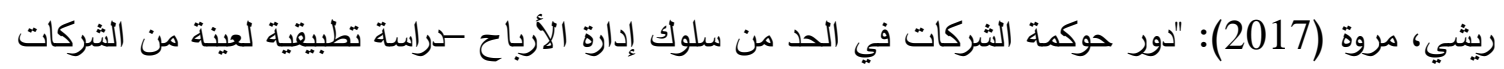

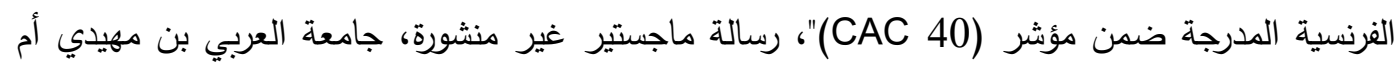

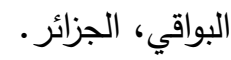

عزى، حضر (2008): "فعالية الحكم الراشد -الحوكمة-في تفعيل خصخصة الثركات إثارة على واقع الخصخصة في الجزائر"، ورقة مقدمة إلى المؤتمر العلمي الأول حول حوكمة الشركات ودورها في في لفيل الاصلاح الاقتصادية، جامعة دمشق، سوريا. عورتاني، هشام وموسى، نائل (2003): "دليل منهجية الإدارة في المنشآت التجارية المعاصرة"، مركز تطويل القطاع الخاص، فلسطين. الفضل، مؤيد محمد علي وحمد، مجيد عبد زيد (2015): "حوكمة الثركات ودورها في الحد من إدارة الأرباح -

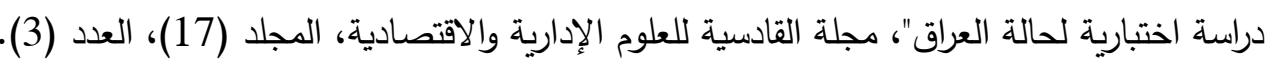
قويدر، أكرم محمد (2015): "مدى التزام الثركات المساهمة العامة في فلسطين بمبادئ الحوكمة"، سالة ماجستير

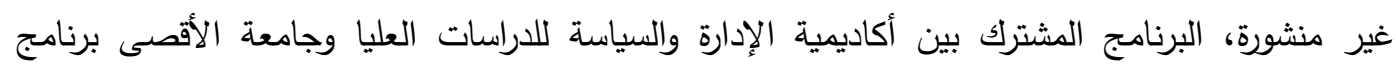
القيادة والإدارة، غزة، فلسطين. الكايد، زهير عبد الكريم (2003): "الحوكمة -قضايا وتطبيقات"، مطبوعات المنظمة العربية للتمية الإدارية،

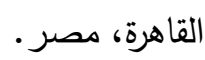
المصطفى، محمد بهيج محمد (2012): "أثر حوكمة الثركات على ممارسة إدارة الأرباح -رراسة تطبيقية على مهر.

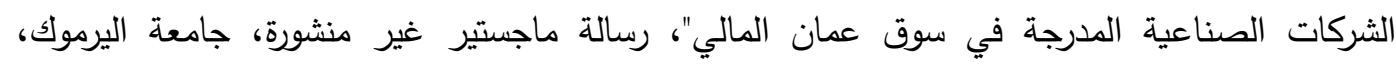

معراج، هواري وآدم، حديدي (2012): "نحو تفعيل دور الحوكمة المؤسسية في ضبط إدارة الأرباح في البنوك

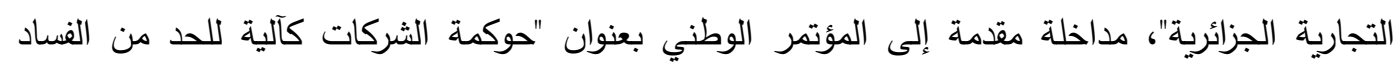
المالي والإداري"، المنعقد في جامعة محمد خضير - كبكرة، كلية العلوم الاقتصادية والتجارية وعلوم التسيير، يومي 6-7 مايو، الجزائر.

منصور، فتح الرحمن الحسن وعلي، علي الصادق أحدد (2014): "دور حوكمة الثركات في الحد من ظاهرة التهرب الضريبي بالتطبيق على ديوان الضرائب الاتحادي بالسودان -ـراسة تحليلية ميدانية"، مجلة العلوم

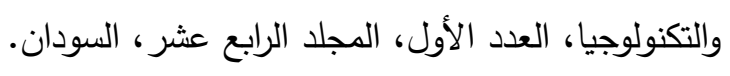

هواري، معراج وحديدي، آدم (2012): "نحو تفعيل الحوكمة المؤسسية في ضبط إدارة الأرباح"، مداخلة في الملتقى كأنى

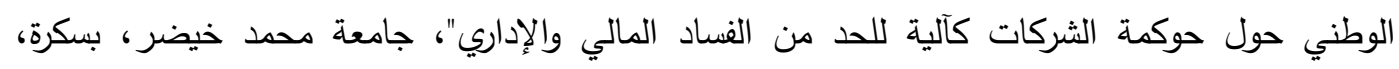
الجزائر

الوزير، جهاد (2007): "دور الحوكمة في تمكين المساهمين والمستثمرين واستقرار الأسواق المالية"، ورقة مقدمة إلى الملتقى السنوي الأول لسوق راس المال الفلسطيني، فلسطين.

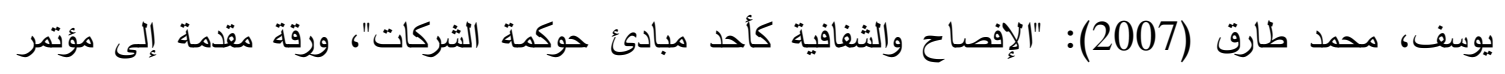
متطلبات حوكمة الشركات وأسواق المال العربية المنعقد في شرم الثيخ في الفترة من (14-16 مايو)، جمهورية مصر العربية. 


\section{References}

Abu Ajila, Imad Muhammad and Hamdan, Allam Muhammad (2009). The Impact of Institutional Governance on Profits Management - Evidence from Jordan", Working Paper of the International Scientific Forum on the Financial Crisis, Economics and Financial Governance, Faculty of Economics and Management Sciences, Farhat Abbas University, Algeria.

Al Wazeer, Jihad. (2007). The Role of Governance in Empowering Shareholders and Investors and the Stability of Financial Markets. A paper presented at the First Annual Forum of the Palestinian Capital Market, Palestine.

Alamgir, M. (2007). Corporate Governance: A Risk Perspective. In Governance and Reform, a conference organized by the Egyption Banking institute, Gairo (Vol. 227, p. 45). https://doi.org/10.1504/IJMFA.2018.091659

Alareeni, B. (2018). The impact of firm-specific characteristics on earnings management: evidence from GCC countries. International Journal of Managerial and Financial Accounting, 10(2), 85-104.

Alareeni, B. (2019). A Review of Auditors' GCOs, Statistical Prediction Models and Artificial Intelligence Technology. International Journal of Business Ethics and Governance, 2(1), 19-31. https://doi.org/10.51325/ijbeg.v2i1.30

Alareeni, B. (2018). Does corporate governance influence earnings management in listed companies in Bahrain Bourse?, Journal of Asia Business Studies, 12(4),551-570. https://doi.org/10.1108/JABS-06-2017-0082

Alareeni, B., \& Aljuaidi, O. (2014). The modified Jones and Yoon models in detecting earnings management in Palestine Exchange (PEX). International Journal of Innovation and Applied Studies, 9(4), 1472.

Alareeni, B., \& Branson, J. (2013). Predicting Listed Companies' Failure in Jordan Using Altman Models: A Case Study. International Journal of Business and Management, 8(1), 113-126. https://doi.org/10.5539/ijbm.v8n1p113

Alareeni, B.A. (2019). The associations between audit firm attributes and audit qualityspecific indicators: A meta-analysis, Managerial Auditing Journal, 34(1),6-43. https://doi.org/10.1108/MAJ-05-2017-1559

Al-Assarj, Hussein Abdel-Muttalib. (2012). Endowment Funds Governance Between Theory and Practice. [Unpublished Master's Thesis], National Planning Institute, Egypt.

Al-Fadl, Muayad Muhammad Ali and Hamad, Majeed Abd Zaid. (2015). Corporate governance and its role in limiting profits management - an experimental study of the iraq case. Al-Qadisiyah Journal of Administrative and Economic Sciences, 17(3).

Ali Shah, S. Z., Butt, S. A., \& Hassan, A. (2009). Corporate governance and earnings management an empirical evidence form Pakistani listed companies. European Journal of Scientific Research, 26(4), 624-638.

Al-Kayed, Zuhair Abdel-Karim. (2003). Governance - Issues and Applications. Arab Administrative Development Organization Publications, Cairo, Egypt.

Al-Mustafa, Muhammad Bahij Muhammad. (2012). The Impact of Corporate Governance on Profit Management Practice - An Empirical Study on Industrial Companies Listed in Amman Financial Market. [Unpublished Master Thesis], Yarmouk University, Jordan.

Alqallaf, H. and Alareeni, B. (2018). Evolving of Selected Integrated Reporting Capitals among Listed Bahraini Banks, International Journal of Business Ethics and Governance, 1(1), 15-36. https://doi.org/10.51325/ijbeg.v1i1.10 
Awartani, Hisham and Moussa, Nael. (2003). A Guide to Management Methodology in Contemporary Commercial Enterprises. Center for the Development of the Private Sector, Palestine.

Azza, Hadar. (2008). The Effectiveness of Good Governance - Governance - in Activating the Privatization of Companies as a Sign of the Reality of Privatization in Algeria. Paper presented at the First Scientific Conference On Corporate Governance and its Role in Economic Reform, Damascus University, Syria.

Bedard, J. C., \& Biggs, S. F. (1991). The effect of domain-specific experience on evaluation of management representations in analytical procedures. Auditing- $a$ Journal of Practice \& Theory, 10, 77-90.

Burgstahler, D., \& Dichev, I. (1997). Earnings management to avoid earnings decreases and losses. Journal of accounting and economics, 24(1), 99-126. https://doi.org/10.1016/S0165-4101(97)00017-7

DeAngelo, L. E. (1986). Accounting numbers as market valuation substitutes: A study of management buyouts of public stockholders. Accounting review, 400-420.

Dechow, P. M., \& Sloan, R. G. (1991). Executive incentives and the horizon problem: An empirical investigation. Journal of accounting and Economics, 14(1), 51-89. https://doi.org/10.1016/0167-7187(91)90058-S

Dechow, P. M., Sloan, R. G., \& Sweeney, A. P. (1995). Detecting earnings management. Accounting review, 193-225.

Dennis, M. 2007. Audit quality: An analysis of management, auditor, and environmental factors. Ph.D., University of Arkansas, 168 pages; AAT 3257883

Freeland, C (2007). Basel Committee Guidance on Corporate Governance for Banks, paper presented at: Coorporate Governance and Reform: Paving the Way to Financial Stability and Development, a conference organized by the Egyptian Banking Institute, Cairo, May 7-8.

González, J. S., \& García-Meca, E. (2014). Does corporate governance influence earnings management in Latin American markets?. Journal of Business Ethics, 121(3), 419-440. https://doi.org/10.1007/s10551-013-1700-8

Haidar, J. I. (2009). Investor protections and economic growth. Economics Letters, 103(1), 1-4. https://doi.org/10.1016/j.econlet.2008.12.007

Hammoudi, Asmaa. (2015). The Quality of Accounting Information in Activating Corporate Governance - Case Study of the Manufactured Metal Structures Construction Company Oum El Bouaghi. [Unpublished Master Thesis], University of Oum El Bouaghi, Algeria.

Healy, P. M. (1985). The effect of bonus schemes on accounting decisions. Journal of accounting and economics, 7(1-3), 85-107. https://doi.org/10.1016/0165$\underline{4101(85) 90029-1}$

Houari, Miraj and Hadidi, Adam. (2012). Towards activating corporate governance in controlling profit management. Paper presented at the National Forum on Corporate Governance as a Mechanism to Reduce Financial and Administrative Corruption, Mohamed Khaider University, Biskra, Algeria.

Jensen, M. C. (1993). The modern industrial revolution, exit, and the failure of internal control systems. the Journal of Finance, 48(3), 831-880. https://doi.org/10.1111/j.1540-6261.1993.tb04022.x

Jensen, M. C., \& Meckling, W. H. (1976). Theory of the firm: Managerial behavior, agency costs and ownership structure. Journal of financial economics, 3(4), 305360. https://doi.org/10.1016/0304-405X(76)90026-X

Jones, J. (1991). Earning Management During Import Relief Investigations, Journal of Accounting Research, 29 (2), 193-228. https://doi.org/10.2307/2491047 
Kwaider, Akram Muhammad. (2015). The Extent of Public Shareholding Companies' Commitment to the Principles of Governance in Palestine. [Unpublished Master Thesis], Al-Aqsa University Leadership and Management Program, Gaza, Palestine.

Levitt, A. (1998). The numbers game, speech delivered at the NYU Center for Law and Business, New York, 28 September, available at: www.sec.gov.

Mansour, Fateh Al-Rahman Al-Hassan and Ali, Ali Al-Sadiq Ahmed. (2014). The role of corporate governance in limiting the phenomenon of tax evasion by application to the Federal Tax Office in Sudan - a field analysis study. Journal of Science and Technology, 14(1).

Mirag, Houari and Adam, Hadidi. (2012). Towards Activating the Role of Institutional Governance in Controlling Profit Management in Algerian Commercial Banks, an intervention presented at the National Conference entitled "Corporate Governance as a Mechanism for Reducing Financial and Administrative Corruption", held at Mohamed Khoudair University - Biskra, Faculty of Economic, Business and Management Sciences, 6-7 May, Algeria.

Mitani, H. (2010). Additional Evidence on Earnings Management and Corporate Governance, FRTC, February, 2010.

Osma, Beatriz Garcia and Belen, Gill De Albornoz Noguer, (2005). Corporate Governance and Earning Management in Spain, 28th Congress Annual European Accounting Association, Goteborg.

Petroni, K. (1992). Optimistic Reporting in the Property-Casualty Insurance Industry, Journal of Accounting and Economics, 15(4), 485- 508. https://doi.org/10.1016/0165-4101(92)90003-K

Ramachandran, J., Ngete, Z. A., Subramanian, R., \& Sambasivan, M. (2015). Does corporate governance influence earnings management? Evidence from Singapore. The Journal of Developing Areas, 263-274. https://doi.org/10.1353/jda.2015.0169

Rishi, Marwa. (2017). The Role of Corporate Governance in Limiting Profits Management Behavior - An Empirical Study of a Sample of French Companies Included in the CAC 40 Index. [Unpublished Master's Thesis], University of AlArabi Bin Mahidi Oum El-Bouaghi, Algeria.

Talahma, Khaled Ibrahim. (2012). Corporate Governance in Palestine - Theory and Practice. The Jordanian Journal of Law and Political Science, 4(3).

Youssef, Mohamed Tariq. (2007). Disclosure and Transparency as one of the Principles of Corporate Governance. A paper presented at the Conference on Corporate Governance Requirements and Arab Capital Markets held in Sharm El-Sheikh from (14-16 May), Arab Republic of Egypt

Zulfiqar, S., Shah, A., Butt, S., and Bin Tariq, Y., (2011). Use or abuse of creative accounting techniques, International Journal of Trade, Economics and Finance, 2 (6), 531- 536 https://doi.org/10.7763/IJTEF.2011.V2.161 